\title{
Recovery Act: Molecular Simulation of Dissolved Inorganic Carbons for Underground Brine CO2 Sequestration
}

\author{
Final Report Period: 12-1-09 to 11-30-12 \\ PI: Prof. William A. Goddard III \\ Issue date: December, 2012 \\ DOE AWARD NUMBER: DOE-ARRA-DE-FE0002057-brine \\ California Institute of Technology \\ 1201 E. California Blvd, Pasadena, CA 91125
}




\section{Disclaimer:}

This report was prepared as an account of work sponsored by an agency of the United States Government. Neither the United States Government nor any agency thereof, nor any of their employees, makes any warranty, express or implied, or assumes any legal liability or responsibility for the accuracy, completeness, or usefulness of any information, apparatus, product, or process disclosed, or represents that its use would not infringe privately owned rights. Reference herein to any specific commercial product, process, or service by trade name, trademark, manufacturer, or otherwise does not necessarily constitute or imply its endorsement, recommendation, or favoring by the United States Government or any agency thereof. The views and opinions of authors expressed herein do not necessarily state or reflect those of the United States Government or any agency thereof. 


\section{TABLE OF CONTENTS}

Recovery Act: Molecular Simulation of Dissolved Inorganic Carbons for Underground Brine $\mathrm{CO} 2$ Sequestration

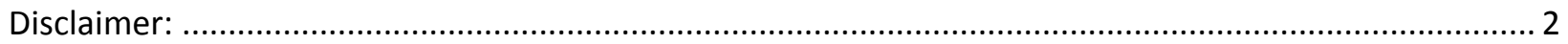

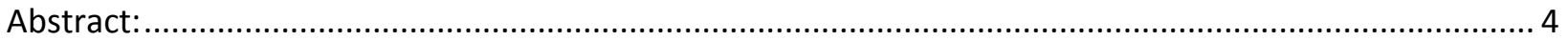

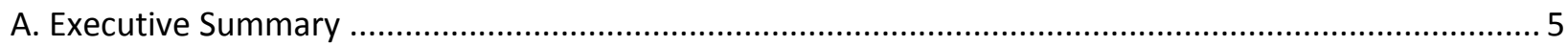

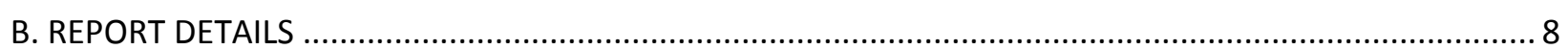

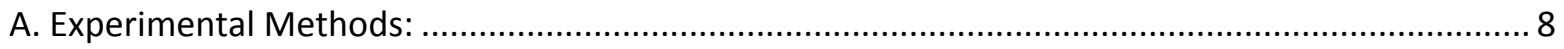

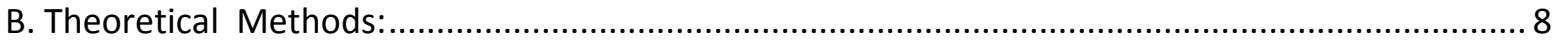

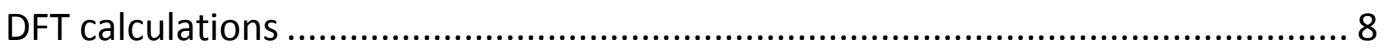

Classical MD simulations with empirical potentials ........................................ 9

Forcefield fitting using Genetic Algorithms ................................................... 9

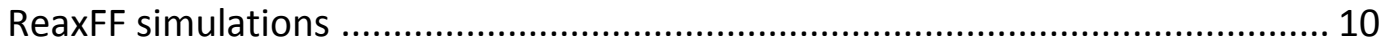

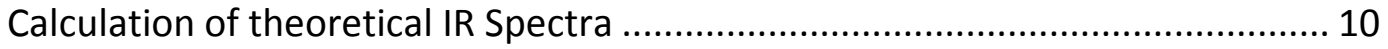

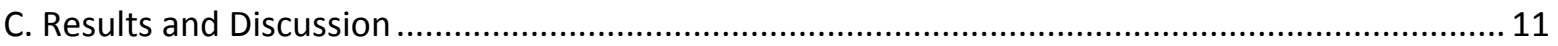

C.1.A Verification of DFT simulation through CO2 dissolved Mid-IR spectra....... 11

C.1.B. Vibrational Spectra of the $\mathrm{CO} 2-\mathrm{H} 2 \mathrm{O}$ dimer ......................................... 11

C.1.C. DFT simulation for $\mathrm{HCO}_{3}{ }^{-}$Mid-IR spectra ............................................ 12

C.2. Experimental proof of the simulated spectra.............................................. 14

C.3.A. Evaluation of the ReaxFF forcefield for DIC species................................. 15

C.3.B. Optimization of ReaxFF to match results from QM DFT simulation .......... 19

C.3.C. ReaxFF simulation for DIC Mid-IR spectra under high pressure and

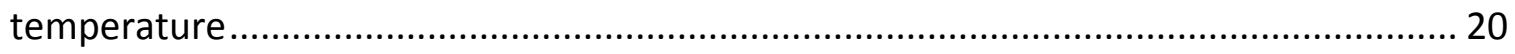

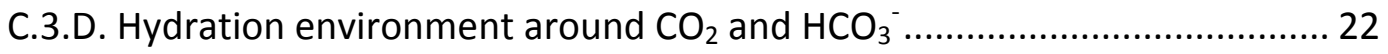

C.3.E. IR spectra of DICs under various temperature and pressure conditions ... 24

C.4.A. ReaxFF simulation of high salinity water.............................................. 25

C.4.B. Thermodynamic Stability of DIC in water/brine..................................... 26

C.5. DIC species' MIR spectra under high salinity conditions ........................... 27

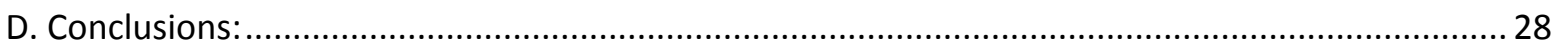

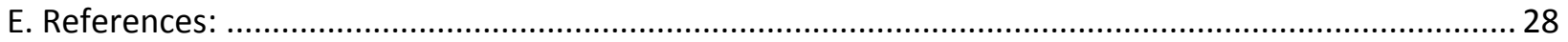




\section{ABSTRACT:}

To further our understanding and develop the method for measuring the DICs under geological sequestration conditions, we studied the infrared spectra of DICs under high pressure and temperature conditions. First principles simulations of DICs in brine conditions were performed using a highly optimized ReaxFF-DIC forcefield. The thermodynamics stability of each species were determined using the 2PT method, and shown to be consistent with the Reax simulations. More importantly, we have presented the IR spectra of DIC in real brine conditions as a function of temperature and pressure. At near earth conditions, we find a breaking of the $\mathrm{O}-\mathrm{C}-\mathrm{O}$ bending modes into asymmetric and symmetric modes, separated by $100 \mathrm{~cm}^{-1}$ at $400 \mathrm{~K}$ and $5 \mathrm{GPa}$. These results can now be used to calibrate FTIR laser measurements. 


\section{A. EXeCuTIVE Summary}

The accelerating rate of climate change, caused by increased $\mathrm{CO} 2$ concentration in the atmosphere, poses a most serious risk to human livelihood on this planet. Recent metrological events and extreme weather conditions have emphasize the degree to which current and future changes in climate will be expensive, both in terms of economy and human lives. It is therefore imperative that effective solutions for sequestering $\mathrm{CO} 2$ from the atmosphere be immediately implemented in the short term, in concert with longer term strategy that focuses on reduced greenhouse emissions from industrial and transportation processes.

To this end, underground storage of $\mathrm{CO}_{2}$ in brine is one of the more promising strategies for removing large amounts of $\mathrm{CO} 2$ from the atmosphere, due to large storage area for sequestration and the availability of mature techniques for accomplishing this task. Dissolved/Total Inorganic Carbon (DIC/TIC) includes 4 forms of dissolved $\mathrm{CO}_{2}$, i.e. $\mathrm{CO}_{2}$ (aq), $\mathrm{H}_{2} \mathrm{CO}_{3}, \mathrm{HCO}_{3}$, and $\mathrm{CO}_{3}{ }^{2-}$. They distribute in water according to following balances along with $\mathrm{CO} 2$ in the air (CO2(g)): $\mathrm{CO}_{2}(\mathrm{aq}) \stackrel{\mathrm{Kr}}{\Leftrightarrow} \mathrm{H}_{2} \mathrm{CO}_{3} \stackrel{\mathrm{K} 1}{\Leftrightarrow}[\mathrm{HCO} 3-] \stackrel{\mathrm{K} 2}{\Leftrightarrow}\left[\mathrm{CO}_{3}^{-2}\right]$, with equilibrium constants $\mathrm{k}_{\mathrm{r}}, \mathrm{k}_{1}$ and $\mathrm{k}_{2}$ that is a function of $\mathrm{pH}$, temperature and pressure.

Any $\mathrm{CO} 2$ sequestration project, where large amount of $\mathrm{CO}_{2}$ injected into underground brine water body will need to be monitored, verified and accounted, needs online measurements of DIC in brine water deep underground in underground brine. This is important in order to accurately identify the geological area affected by this technology (and thus gauge the ecological impact) and quantifies the exact amount of $\mathrm{CO} 2$ that is being stored by this technique.

Both of these goals cannot be realized by the most popular geological technology that relies on monemeter. Here the gaseous sample is expanded in a measurement chamber and the $\mathrm{CO} 2$ content calculated from the measured equilibrium temperature and pressure. In addition to not being sensitive to the other DIC species other than $\mathrm{CO} 2$, this technique is expensive and time consuming, and so does not measure the amount of dissolved $\mathrm{CO} 2$ at higher pressures and temperatures. Other techniques, such as capillary-type isotachophoresis[1], the use of a modified gas analyzer[2], flow injection analysis systems[3, 4], the use of a gas electrode with an air gap, and a $\mathrm{pH}$ meter, lack robustness and simplicity, which hinders their application in underground brine sequestration MVA. A selective, direct spectroscopic method that could be deployed underground is therefore of considerable practical interest for $\mathrm{CO} 2$ sequestration.

$\mathrm{CO}_{2}$ dissolved in water gives rise to a strong and characteristic absorption band at $2,342 \mathrm{~cm}^{-1}[5]$ meaning that modern infrared spectroscopic techniques might be a useful detection and quantification tool, especially when considering recent innovations such as roomtemperature quantum cascade lasers[6] that allows transmission measurements at extended optical paths. However, when one comes to measuring DIC species using the MIR spectrum there is a great void in the available experimental and theoretical Mid-IR absorption spectra of $\mathrm{CO} 2$ (aq), $\mathrm{H}_{2} \mathrm{CO}_{3}, \mathrm{HCO}_{3}{ }^{-}$and $\mathrm{CO}_{3}{ }^{2-}$ in water. The majority of theoretical simulations also only deal with gas phase or clusters of these $\mathrm{CO}_{2}$ species[7]. There is $\mathrm{MD}$ simulation of hydrogenbonds in these $\mathrm{CO} 2$ species in water[8], but no spectra were given. The exact spectra will also change when the external pressure, temperature, $\mathrm{pH}$ and salinity of the water change. Therefore, it is essential to first conduct a survey simulation of the spectra --- identifying the features that could be measured with the "limited-transparent" windows of $\mathrm{H}_{2} \mathrm{O}$, both position and strength of the features are needed. Second, we need to have accurate knowledge of how the spectra could 
change as the external factors, i.e. pressure, temperature, $\mathrm{pH}$ and salinity change. This will help the calibration of the experimental data.

Thus the major goal of this project was to develop a modern computational framework for simulation of DIC solutions under extreme temperatures and pressures, $\mathrm{pH}$ and salinity, the determining of the speciation of DICs at these conditions, and calculation of the associated IR spectra. Our approach is to base the fundamental interactions in the system on high level quantum mechanical (QM) calculations and develop reactive forcefield (ReaxFF-DIC) capable of simulating length and timescale not accessible to QM techniques. The optimization of the parameters for ReaxFF-DIC was accomplished by constrained minimization in parameter space using Genetic Algorithms. Our approach has the advantage of be ab-initio, i.e. it does not rely on experimental data and thus capable of being predictive, describing systems not imagined by or inaccessible to experiments with the fidelity of QM. Our optimization procedure is multidimensional and produces a family of parameters each satisfying a particular initial condition. Therefore it is important to validate the parameters in our potentials by direct comparison to experiments where available. Additionally, we calculated the IR spectra of DICs from our various Reax-DIC simulations and provide for the first time the spectra as a function of temperature and pressure.

From the associated molecular trajectories of our ReaxFF-DIC simulations, we can access the system thermodynamics using the Two-Phase Thermodynamics method[9-11] developed at Caltech, which has been recently applied to studying the stability of hydrocarbons at deep Earth pressures and temperatures[12]. This method allows for a complete description of the entropy and enthalpy effects that determine the stability of the DIC species in water, under varying conditions of brine concentration, temperature and pressure.

Thus the major achievement of the project were

1. Development of a first-principles Reactive forcefield (ReaxFF-DIC) from Genetic Algorithm fitting high level QM gas phase structures and reaction of CO2 and the associated carbonates

2. Simulation of DICs under extreme pressure and temperatures and varying salinity for hundreds of nanoseconds

3. Assessment of the thermodynamic stability of the various DICs species under conditions of varying temperature, pressure and salinity

4. Computation of the associated IR spectra of the DIC species based on monitoring the time-varying dipole moment vector and linear response theory[13]

Our simulations, thermodynamic information and IR spectra represent the first of such calculations on DICs. Indeed, we have gained insights into the solvation of DICs under extreme temperature and pressure and with varying salt content, such as:

1. $\mathrm{CO}_{2}$ is the preferred species of DICs with increasing temperature and pressure

2. Solvated $\mathrm{CO}_{2}$ molecules exists predominately as $\mathrm{CO}_{2}\left(\mathrm{H}_{2} \mathrm{O}\right)_{18}$ motifs in solution

3. decrease in the solubility of $\mathrm{CO}_{2}$ with increased brine concentrations and. the population of $\mathrm{HCO}_{3}{ }^{-}$increases relative to the $\mathrm{CO}_{2}$ with brine

4. $\mathrm{HCO}_{3}$ - is the preferred species of DICs under high pressure/temperature and high salinity

5. Entropy of the released water molecules stabilizes $\mathrm{HCO}_{3}{ }^{-}$relative to $\mathrm{CO}_{2} / \mathrm{CO}_{3}{ }^{2-}$

6. Enthalpy stabilizes $\mathrm{HCO}_{3}{ }^{-}$relative to $\mathrm{H}_{2} \mathrm{CO}_{3}$ 
These results and particularly the associated IR spectra will now be used to calibrate the experimental lasers for detecting and quantifying the amount of DIC species stored in underground brine reservoirs. 


\section{B. REPORT DETAILS}

\section{A. Experimental Methods:}

The FTIR spectra for different species of $\mathrm{CO}_{2}$ when dissolved in water is measured with a Thermo Nicolet Nexus 470 FTIR equipped with a ATR module (Figure 1). CO2 species in water, i.e. $\mathrm{CO} 2(\mathrm{aq}), \mathrm{H}_{2} \mathrm{CO}_{3}, \mathrm{HCO}_{3}{ }^{-}$and $\mathrm{CO}_{3}{ }^{2-}$, are trapped in a cotton ball and then put on top of the diamond tip of the ATR module.

All spectra were collected with 32 averages at either $4 \mathrm{~cm}^{-1}$ resolution. The concentration of the $\mathrm{HCO}_{3}{ }^{-}$and $\mathrm{CO}_{3}{ }^{2-}$ are prepared in test tube/vials, and then transferred to cotton ball tip, then acid is added to convert the $\mathrm{HCO}_{3}{ }^{-}$and $\mathrm{CO}_{3}{ }^{2-}$ into $\mathrm{CO} 2(\mathrm{aq})$ and $\mathrm{H}_{2} \mathrm{CO}_{3}$. So, the initial concentrations of $\mathrm{HCO}_{3}{ }^{-}$and $\mathrm{CO}_{3}{ }^{2-}$ is accurate as prepared, while the concentration of $\mathrm{HCO}_{3}{ }^{-}$and $\mathrm{CO}_{3}{ }^{2-}$ along with $\mathrm{CO} 2(\mathrm{aq})$ and $\mathrm{H}_{2} \mathrm{CO}_{3}$ are varying after $\mathrm{HCl}$ acid is applied.

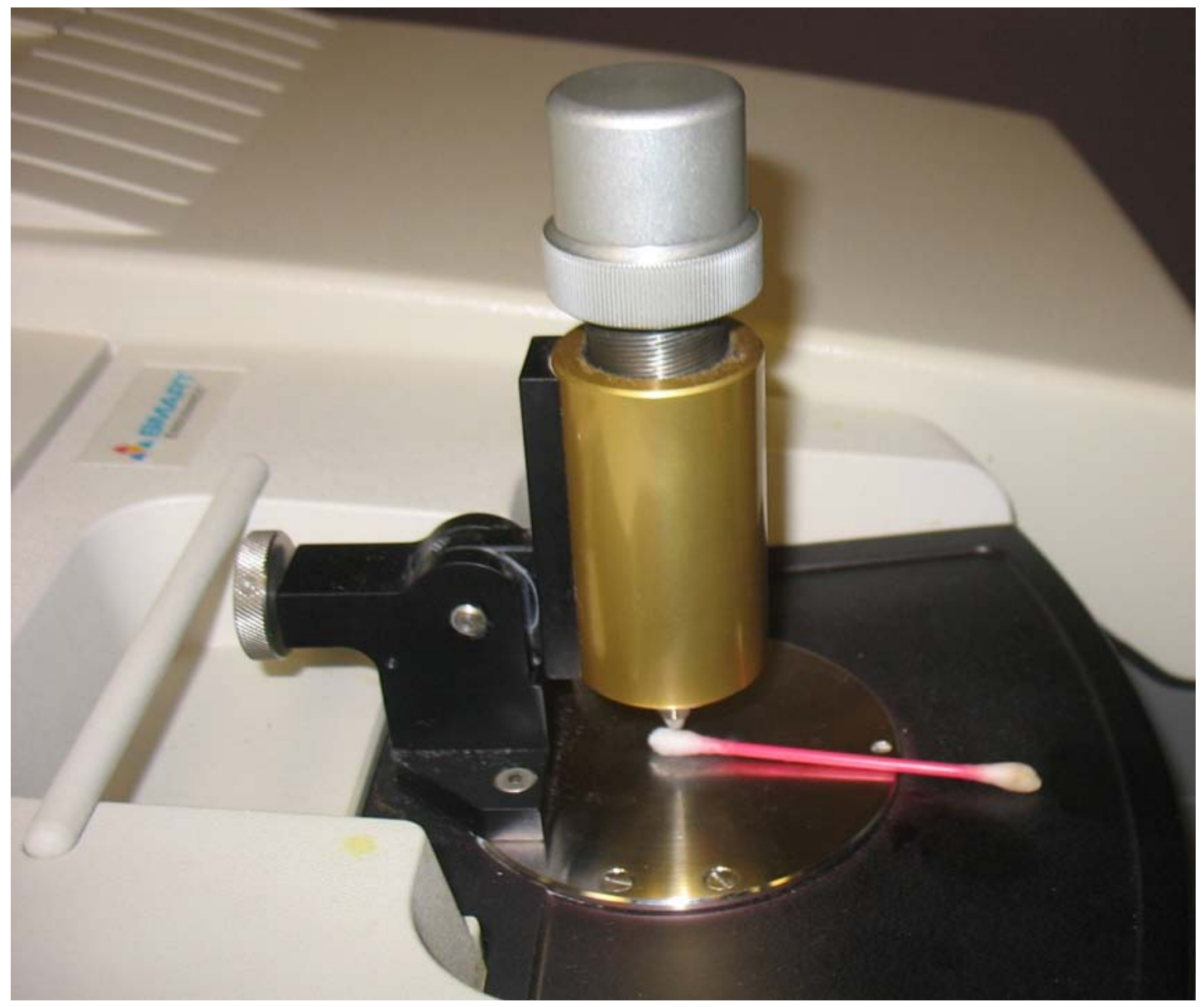

Figure 1: ATR module for experimental FTIR spectra measurements.

\section{B. Theoretical Methods:}

\section{DFT calculations}

DFT QM electronic structure calculations were performed, using the Jaguar 7.0 QM package and the augmented split-valence double (aug-cc-pVDZ) and triple (aug-cc-pVTZ) zeta 
basis set of Dunning and coworkers. We tested the accuracy of the B3LYP, X3LYP, M06, M06$2 \mathrm{X}$ and M06-HF DFT functionals in predicting the vibrational frequencies of $\mathrm{CO} 2$ and $\mathrm{H}_{2} \mathrm{O}$ in the gas phase and in implicit solvation, using the PDF module in the Jaguar 7.0 package.

\section{Classical MD simulations with empirical potentials}

Constant pressure - constant temperature (NPT) molecular dynamics simulations were performed using the LAMMPS MD code. We used a Nose-Hoover thermostat with a temperature coupling constant of 0.1 ps and a barostat with a pressure piston constant was 2.0 ps. The integration time step was set to $1 \mathrm{fs}$. The equations of motion used are those of Shinoda et al.[14], which combine the hydrostatic equations of Martyna et al.[15] with the strain energy proposed by Parrinello and Rahman[16]. The time integration schemes closely follow the timereversible measure-preserving Verlet integrators derived by Tuckerman et al.[17] Long-range Coulombic interactions were calculated using the particle-particle particle-mesh Ewald method $^{[18,19]}$ (with a precision of $10^{-5} \mathrm{kcal} / \mathrm{mol}$ ), while the van der Waals interaction were computed with a cubic spline (inner cutoff of $9 \AA$ and an outer cutoff of $10 \AA$ ).

\section{Forcefield fitting using Genetic Algorithms}

We optimized the $\mathrm{C}, \mathrm{O}$ and $\mathrm{H}$ ReaxFF parameters for use in DIC simulations using evolutionary algorithms (EA). All 10 of the CO2/H2O and HCO3-/H2O energy minimized QM structures were used as input, with the initial parameter coming from the ReaxFF forcefield for hydrocarbons. These parameters were modeled by a chromosome of 39 real numbers (genes), representing the valence (bonds and angles) and nonbonded interactions common in the ReaxFF forcefield. New chromosomes were randomly created to generate the initial population. Each parameter is allowed to vary between $+/-10 \%$, as we found that this bound was flexible enough to obtain diverse chromosomes while stringent enough to constrain the parameter space to physically realistic values.

After creating the initial population, new populations are generated according the too method of Courcot and Bridgeman[20] as shown in figure 2:

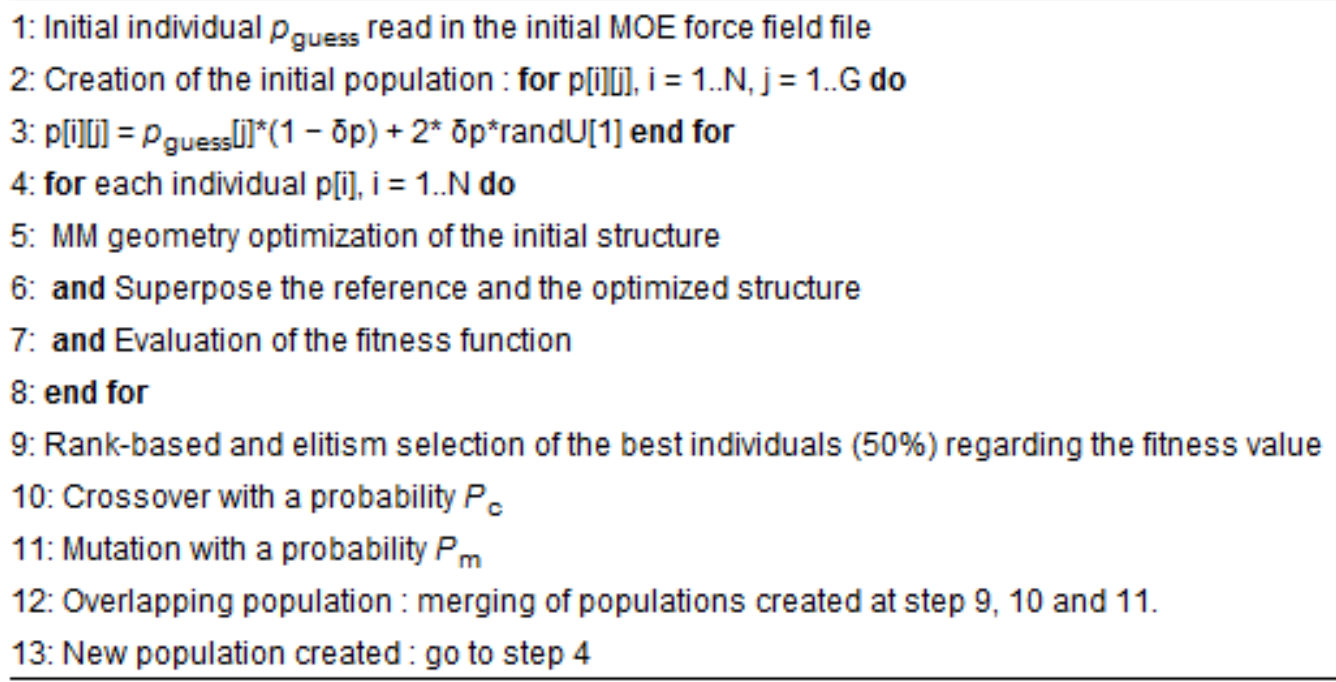

Figure 2: Pseudo-Code the EA Main Function. Copied from reference [20]. 
The fitness function is the difference between the QM and ReaxFF energies at each interaction. Thus our EA scheme will act to minimize this difference and give optimal parameters.

\section{ReaxFF simulations}

We use the ReaxFF-DIC forcefield and the LAMMPS MD simulation engine to simulate the effect of pressure and temperature on the stability of DIC species in water. $40 \mathrm{CO}_{2}$ and $\mathrm{HCO}_{3}{ }^{-}$molecules are randomly distributed in the center of a pre-equilibrate box of 2000 water molecules (representing 0.91M initial concentration), described using the ReaxFF forcefield for water. The initial system was equilibrated using our standard approach[21-30], heated to the required temperatures (300 and 350K) with a Nose-Hoover thermostat and simulated at 1 and 25GPa for 10ps using a Andersen barostat. The snapshot of the system with an average pressure closest to the target was selected for a further 100ps constant volume simulation. The simulation integration timestep was $0.25 \mathrm{fs}$ in all cases. Snapshot of the system during the last 100ps of dynamics was saved every 0.1 ps for post trajectory analysis.

\section{Calculation of theoretical IR Spectra}

\section{i. Calculation of a time varying dipole moment vector of the entire system once equilibrated}

Given the dipole moment of the system after equilibration $\mu\left(\mathrm{r}_{1}, \ldots, \mathrm{r}_{\mathrm{N}} ; \mathrm{q}_{1}, \ldots, \mathrm{q}_{\mathrm{N}}\right)$, which is a function of the atomic positions ( $r$ ) and charges $(q)$, we calculated the dipole moment of the system as a function of time

$$
\mu(\mathrm{t})=\int_{0}^{\mathrm{t}} \mu\left[\mathrm{r}_{1}(\mathrm{t}) * \mathrm{q}_{1}(\mathrm{t}), \ldots, \mathrm{r}_{\mathrm{N}}(\mathrm{t}) * \mathrm{q}_{\mathrm{N}}(\mathrm{t}),\right.
$$

\section{ii. Derivation of the infrared spectra using Linear response theory}

For a system at equilibrium, we relate the spectrum of fluctuations which the time varying dipole moment $\mu(t)$ undergoes to the spectrum of the response to an external oscillating electric field[31]:

$$
\begin{aligned}
& \alpha(\omega)=\frac{4 \pi^{2} \omega\left[1-e^{-\beta h \omega}\right]}{3 h c n} I(\omega), \\
& \text { and } \mathrm{I}(\omega)=\frac{1}{2 \pi} \int_{-\omega}^{\omega} \mathrm{e}^{-\mathrm{i} \omega \mathrm{t}}<\mu(0) * \mu(\mathrm{t})>d t,
\end{aligned}
$$

where $\alpha(\omega)$ is the adsorption cross section as a function of angular frequency $\omega, \beta=$ $1 / k_{B} T, k_{B}$ is Boltzmann's constant, $T$ is the temperature, $h$ is Planck's constant, $c$ is the speed of light, $n$ is the refractive index of the medium, $I(\omega)$ is defined as the absorption lineshape and is evaluated for an isotropic medium and $\langle\mu(0) \mu(t)>$ is the ensemble average of the dipole moment time correlation function.

Using the mathematical machinery of the Parseval's and Wiener-Khintchine theorems[32], we compute $\mathrm{I}(\omega)$ from the power spectrum:

$$
I(\omega)=\frac{1}{2 \pi}\left[\lim _{\tau \rightarrow \infty} \frac{1}{2 \tau} \sum_{j=x, y, z}\left|\int_{-\tau}^{\tau} e^{-i \omega t} \mu_{f}(t) d t\right|^{2}\right]
$$

which allows the use of fast Fourier Transforms[33]. 


\section{iii. Averaging of the spectra over several time windows to include dynamic effects}

We find that the dipole moment autocorrelation function converges to zero within 50ps of dynamics. This means that after 50ps, the system loses all memory of initial starting conditions. This allows us to perform ensemble averaging using 50ps windows of uncorrelated trajectories that sample the experimentally accessible phase space.

\section{iv. Application of quantum corrections to the calculated}

Simple quantum corrections are used to bring the classically computed spectra into agreement with theoretical and experimental quantum reality as shown by Berens and Wilson[13]:

$$
\frac{\alpha^{Q}(\omega)}{\alpha^{C}(\omega)}=\frac{\sinh (\beta h \omega / 2)}{\beta h \omega / 2}
$$

\section{Results and Discussion}

\section{C.1.A Verification of DFT simulation through CO2 dissolved Mid-IR spectra}

DFT QM electronic structure calculations were performed, using the Jaguar 7.0 QM package and the augmented split-valence double (aug-cc-pVDZ) and triple (aug-cc-pVTZ) zeta basis set of Dunning and coworkers. We tested the accuracy of the B3LYP, X3LYP, M06, M06$2 \mathrm{X}$ and M06-HF DFT functionals in predicting the vibrational frequencies of $\mathrm{CO} 2$ and $\mathrm{H}_{2} \mathrm{O}$ in the gas phase and in implicit solvation, using the PDF module in the Jaguar 7.0 package. All functionals gave similar performance (within $5 \mathrm{~cm}^{-1}$ of each other). We list the frequencies of the best performer (B3LYP) in Table 1. Both basis sets show reasonable agreement with experiment, with the double zeta predicting the frequencies more accurately on average.

\begin{tabular}{lrrrl}
\hline \multicolumn{5}{c}{ Frequencies $\left(\mathbf{c m}^{-1}\right)$} \\
\hline & Experiment & aug-cc-pVTZ & $\begin{array}{l}\text { aug-cc- } \\
\text { pVDZ }\end{array}$ & assignment \\
$\mathbf{H}_{\mathbf{2}} \mathbf{O}$ & & & & \\
$\mathbf{v} 2$ & 1594.7 & 1628.4 & 1622.3 & symmetric bending \\
$\mathbf{v 1}$ & 3657.1 & 3821.9 & 3803.3 & symmetric stretch \\
$\mathbf{v 3}$ & 3756 & 3947.7 & 3937.5 & antisymmetric stretch \\
$\mathbf{C O}$ & & & & \\
$\mathbf{v 2}$ & 667 & 659 & 655.5 & degenerate bending OCO \\
$\mathbf{v 1}$ & 1388 & 1325.8 & 1305.4 & symmetric stretch OC \\
$\mathbf{v 3}$ & 2349 & 2401.4 & 2379.2 & antisymmetric stretch OC \\
\hline
\end{tabular}

\section{C.1.B. Vibrational Spectra of the $\mathrm{CO}-\mathrm{H} 2 \mathrm{O}$ dimer}

We map the four dimensional potential energy surface (PES) of the CO2-H2O dimer (Figure 2). We find a quadruply degenerate minimum, with the water molecule forming a single hydrogen bond with the $\mathrm{CO} 2$. The calculated vibrational spectra show the characteristic red shift of $5 \mathrm{~cm}-1$ in the vibrational modes arising from this hydrogen bond. 


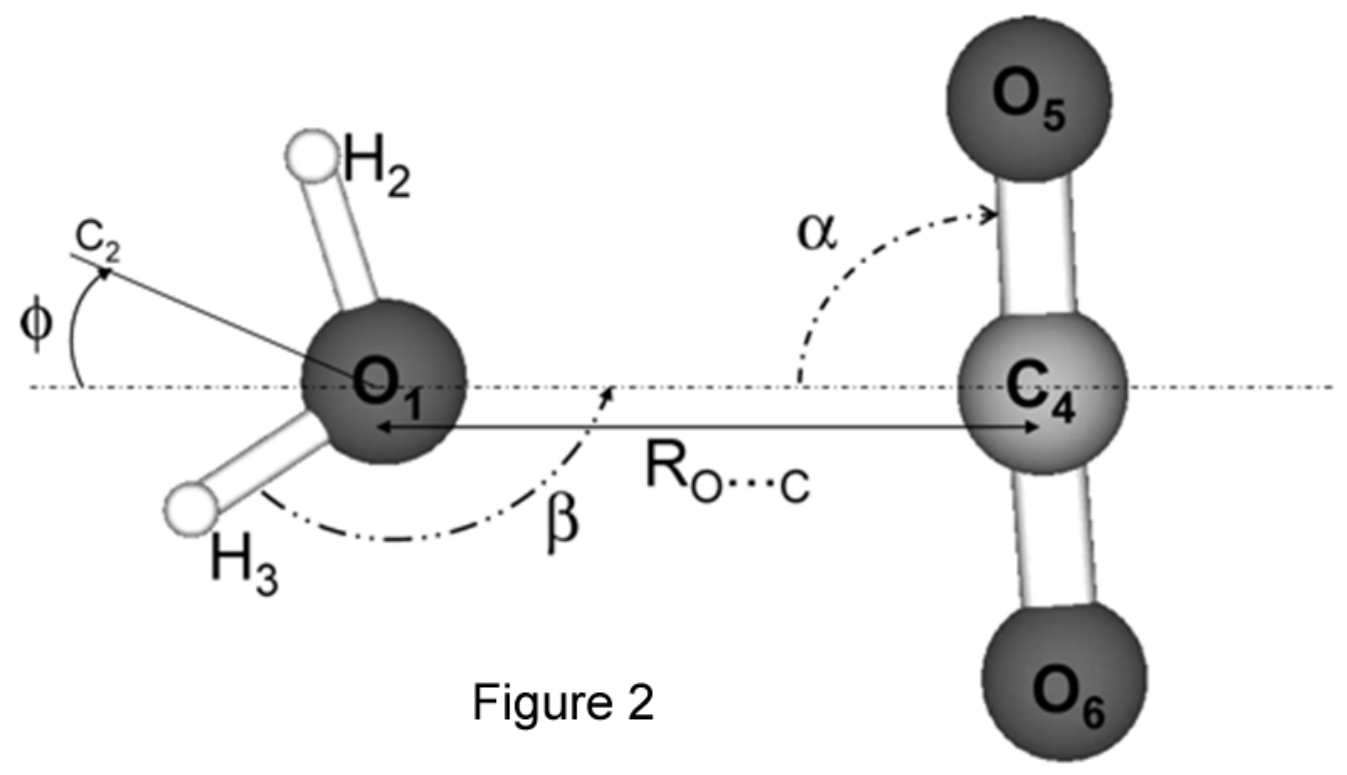

\begin{tabular}{lrrl}
\hline \multicolumn{4}{c}{ Frequencies $\mathbf{( c m}^{-\mathbf{1}} \mathbf{)}$} \\
\hline & aug-cc-pVTZ & \multicolumn{1}{l}{$\begin{array}{l}\text { aug-cc- } \\
\text { pVDZ }\end{array}$} & assignment \\
$\mathbf{v 2 1}$ & 648.8 & 646.6 & in-plane bending \\
$\mathbf{v 2 2}$ & 662.6 & 657.8 & out-of-plane bending \\
$\mathbf{v 1 ( C O )}$ & 1328.6 & 1308.7 & symmetric stretch OC \\
$\mathbf{v 2 ( H O H )}$ & 1626.5 & 1619.2 & symmetric bending \\
$\mathbf{v 3 ( C O )}$ & 2404.4 & 2383.2 & antisymmetric stretch OC \\
$\mathbf{v 1 ( O H )}$ & 3818.5 & 3800.2 & symmetric stretch \\
$\mathbf{v 3 (}(\mathbf{O H})$ & 3944.6 & 3935.3 & antisymmetric stretch \\
\hline
\end{tabular}

\section{C.1.C. DFT simulation for $\mathrm{HCO}_{3}{ }^{-}$Mid-IR spectra}

We prepared clusters of CO2(H2O)x and HCO3-(H2O)x ( $\mathrm{x}=0-10)$ structures by energy minimization using the Dreiding[34] forcefield and the LAMMPS 2010 MD[35] engine. In order to ensure accurate sampling of the potential energy surface, the water molecules were placed in several random configurations for each sized cluster and the top 5 conformers (ranked by total energy) were then selected for electronic structure calculations using the Jaguar 7.5 program[36]. Geometry optimization was initially performed using the X3LYP[37] DFT functional and the augmented polarized triple- $\zeta$ 6-311+G(2df,2p)[38] basis set. The optimized gas phase geometries were then used as input to an implicit solvent calculation with the PBF module in Jaguar, using the accepted parameters of water: dielectric constant: 80.37, density: 0.99823, molecular weight: $18.02 \mathrm{~g} / \mathrm{mol}$, probe radius $1.40 \AA$. Vibrational analysis was performed at all optimized geometries to ensure that the structures corresponded to local minima.

We find that the insolvent $\mathrm{CO} 2$ molecule does not form very stable structure with water. Beyond $\mathrm{CO} 2(\mathrm{H} 2 \mathrm{O})_{3}$, the $\mathrm{CO} 2$ molecule is excluded from the water hydrogen bonding network. In the smaller clusters, we find that the water molecules form a strong hydrogen bond with one of the oxygen on CO2, while the second water molecule in $\mathrm{CO} 2(\mathrm{H} 2 \mathrm{O})_{2}$ hydrogen bonds with the 
first water. The most stable structure is found to be $\mathrm{CO} 2(\mathrm{H} 2 \mathrm{O})_{6}$ and $\mathrm{CO} 2(\mathrm{H} 2 \mathrm{O})_{7}$ (Figure 3).

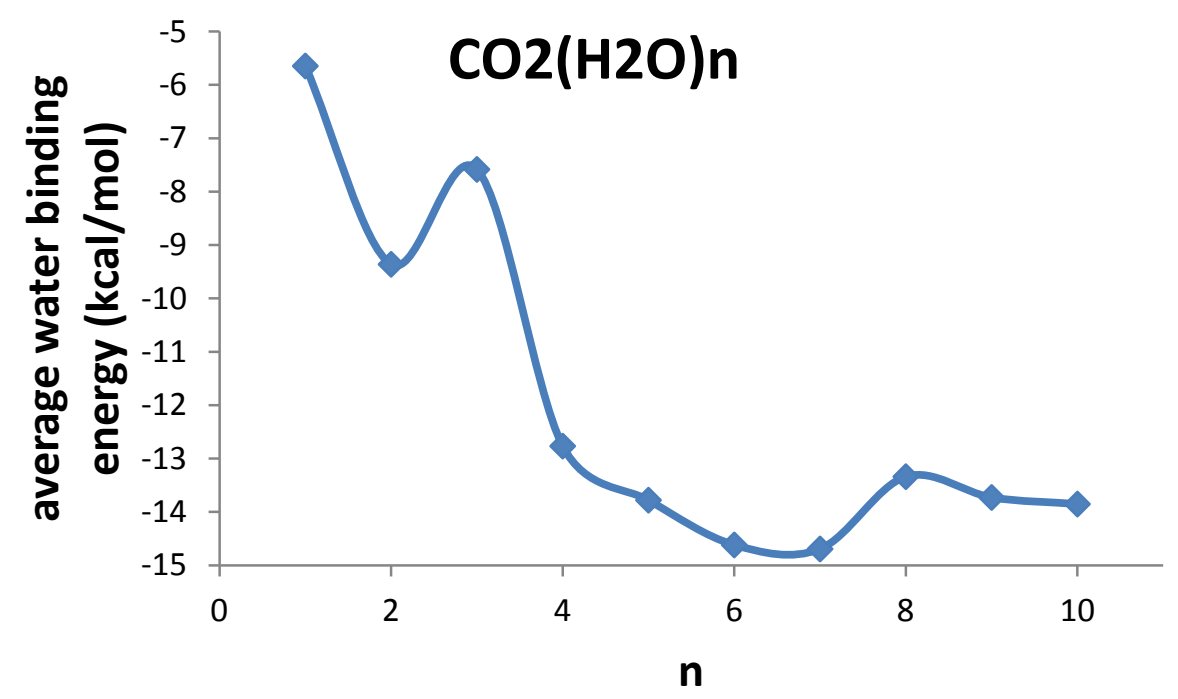

Figure 3: Average water binding energy for $\mathrm{CO} 2(\mathrm{H} 2 \mathrm{O})$ n complexes. The minimum energy structure occur at $n=6$ and $n=7$.

For the HCO3-(H2O)n structures, the first water molecule forms a strong hydrogen bond with the O- group (water is the h-bond donor), the second water forms a hydrogen bond with the $\mathrm{OH}$ group (water is the h-bond acceptor), while the third water forms a weaker h-bond with the double bonded $\mathrm{O}$ group. The forth forms begins a second shell by hydrogen bonding with the first water molecule. The HCO3- is completely solvated by the water shells and we although we find a minima for the $\mathrm{HCO}^{-}(\mathrm{H} 2 \mathrm{O})_{4}$ conformer, the $\mathrm{HCO}^{-}(\mathrm{H} 2 \mathrm{O})_{7}$ conformer and $\mathrm{HCO}^{-}(\mathrm{H} 2 \mathrm{O})_{9}$ conformers are all within $0.5 \mathrm{kcal} / \mathrm{mol}$ (the accuracy of our method) (Figure 4).

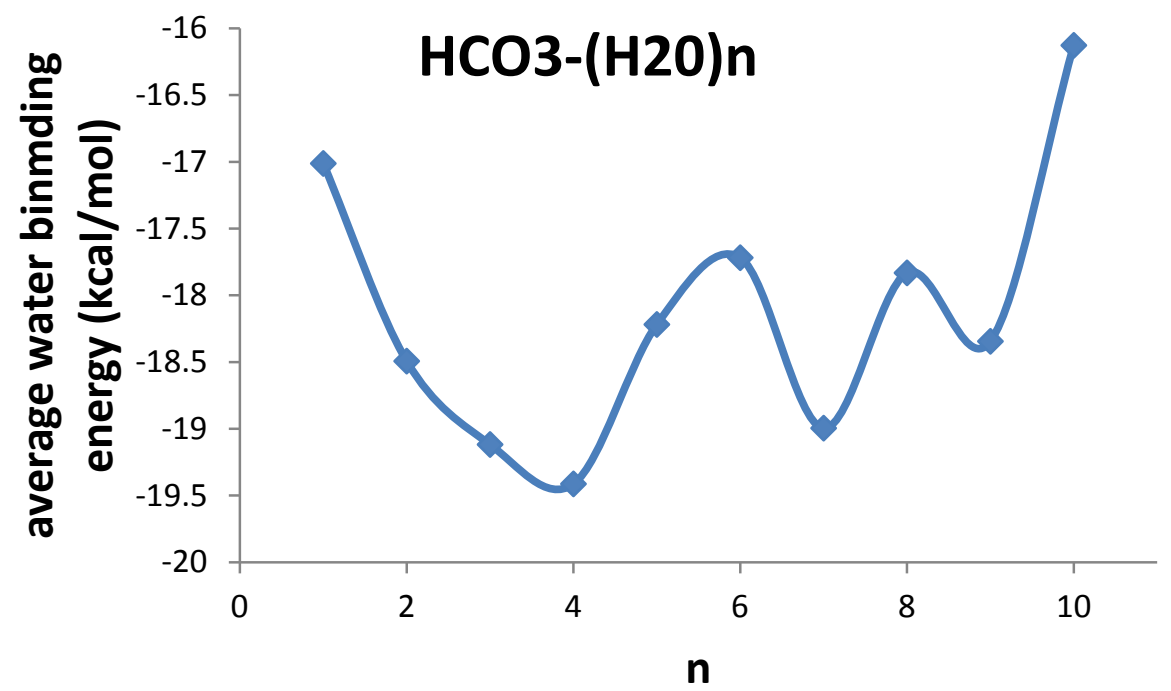

Figure 4: Average water binding energy of the $\mathrm{HCO}^{-}(\mathrm{H} 2 \mathrm{O})_{n}$ complex. The minimum energy structure occurs at $\mathrm{HCO}^{-}(\mathrm{H} 2 \mathrm{O})_{4}$. 
Simulated infrared spectras for the lowest energy complexes were then derived from the B3LYP/6-31G* $(d, p)$ scaled harmonic frequencies (scaling factor: 0.9614). In table 2, we list the shift in the vibrational frequencies of the free molecules with increasing water cluster sizes.

\begin{tabular}{|c|c|c|c|c|c|c|c|c|c|c|c|}
\hline Peak frequ & 422 & 540 & 621 & 743 & 878 & 1160 & 1260 & 1580 & 1588 & 3668 & 3676 \\
\hline $\mathrm{H} 2 \mathrm{O}$ & & & & & & & & \multicolumn{2}{|c|}{$\mathrm{H}-\mathrm{O}-\mathrm{H}$ bending } & $\mathrm{H}-\mathrm{O}-\mathrm{H}$ stret & $\mathrm{H}-\mathrm{O}-\mathrm{H}$ asym \\
\hline $\mathrm{CO} 2$ & & \multicolumn{2}{|c|}{$\mathrm{O}-\mathrm{C}-\mathrm{O}$ bending } & & & & \multicolumn{2}{|c|}{ C-O symmetric stretch } & \multicolumn{3}{|c|}{ C-O asymmetric stretch } \\
\hline $\mathrm{HCO}^{-}$ & $\mathrm{C}-\mathrm{OH}$ rock & -538 & $\mathrm{O}-\mathrm{C}-\mathrm{O}$ bend & $\mathrm{C}-\mathrm{O}-\mathrm{H}$ beng & $\mathrm{C}-\mathrm{OH}$ stretc & In-plane C- & -1255 & Out of plan & -1590 & & \\
\hline
\end{tabular}

Table 2: Vibrational frequencies of isolated molecules in implicit solvent (water). The HCO3frequencies that correspond to the $\mathrm{CO} 2$ modes are given in brackets.

\section{C.2. Experimental proof of the simulated spectra}

The FTIR spectra for different species of $\mathrm{CO}_{2}$ when dissolved in water is measured with a Thermo Nicolet Nexus 470 FTIR equipped with a ATR module (Figure 4). CO2 species in water, i.e. $\mathrm{CO} 2(\mathrm{aq}), \mathrm{H}_{2} \mathrm{CO}_{3}, \mathrm{HCO}_{3}{ }^{-}$and $\mathrm{CO}_{3}{ }^{2-}$, are trapped in a cotton ball and then put on top of the diamond tip of the ATR module.

All spectra were collected with 32 averages at either $4 \mathrm{~cm}^{-1}$ resolution. The concentration of the $\mathrm{HCO}_{3}{ }^{-}$and $\mathrm{CO}_{3}{ }^{2-}$ are prepared in test tube/vials, and then transferred to cotton ball tip, then acid is added to convert the $\mathrm{HCO}_{3}{ }^{-}$and $\mathrm{CO}_{3}{ }^{2-}$ into $\mathrm{CO} 2(\mathrm{aq})$ and $\mathrm{H}_{2} \mathrm{CO}_{3}$. So, the initial concentrations of $\mathrm{HCO}_{3}{ }^{-}$and $\mathrm{CO}_{3}{ }^{2-}$ is accurate as prepared, while the concentration of $\mathrm{HCO}_{3}{ }^{-}$and $\mathrm{CO}_{3}{ }^{2-}$ along with $\mathrm{CO} 2(\mathrm{aq})$ and $\mathrm{H}_{2} \mathrm{CO}_{3}$ are varying after $\mathrm{HCl}$ acid is applied.

We generated the spectra of $\sim 0.1 \mathrm{M} \mathrm{Na2CO3}$ with $\mathrm{H} 2 \mathrm{O}$ background subtracted --- Blue trace; Spectra of $\sim 0.1 \mathrm{M} \mathrm{KHCO3}$ with $\mathrm{H} 2 \mathrm{O}$ background subtracted --- Red trace (figure 5).

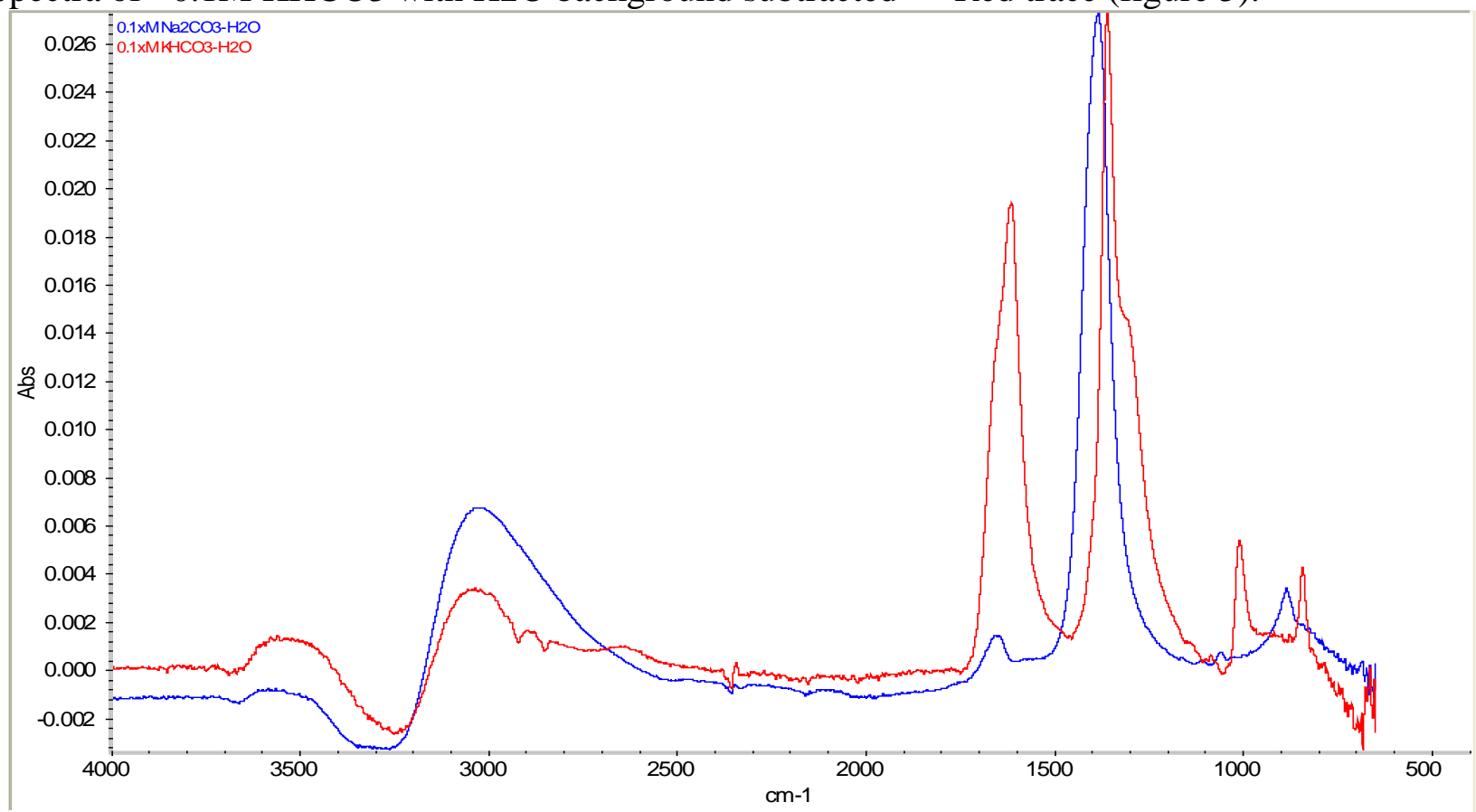

Figure 5: Spectra of 0.1M Na2CO3 with $\mathrm{H} 2 \mathrm{O}$ background subtracted --- Blue trace; Spectra of $\sim 0.1 \mathrm{M} \mathrm{KHCO} 3$ with $\mathrm{H} 2 \mathrm{O}$ background subtracted --- Red trace. 
According to our calculations, we have the following assignment of the peaks:

\begin{tabular}{|l|l|l|l|l|l|l|l|l|l|l|}
\hline Peak Frequency & 840 & 1010 & 1300 & 1360 & 1630 & 890 & 1060 & 1380 & 1680 & 2342 \\
\hline $\mathrm{Na} 2 \mathrm{CO} 3$ & & & & & & $v 2$ & $v 1$ & $v 3$ & $? 2 \times v 2$ & \\
\hline KHCO3 & $v 8$ & $v 5$ & $v 4$ & $v 3$ & $? v 2 / \mathrm{H} 20$ & & & & & \\
\hline $\mathrm{CO} 2$ & & & & & & & & & & $? ?$ \\
\hline
\end{tabular}

Overall, we find good agreement between the simulated spectra and the measured experimental spectras.

\section{C.3.A. Evaluation of the ReaxFF forcefield for DIC species}

The Goddard group has developed the ReaxFF reactive force field [30] to provide nearly the accuracy of ground state QM for describing large-scale, long-term reactive processes at computational costs nearly as low as ordinary force field based MD. ReaxFF has been validated for systems with thousands to millions of atoms[39]. In ReaxFF all parameters are fit directly to QM descriptions of reactions, equations of state, geometries (e.g. coordination) as well as other key system attributes. The functional forms in ReaxFF were selected to provide accurate descriptions of transition states for a variety of allowed and forbidden reactions. Key features of ReaxFF include 1) Environmentally dependent charge distributions (electronegativity, hardness, shielding radius[40]) and 2) Bond order dependent valence terms, and Non-bond or van der Waals (vdw) interactions between all atoms (rather bonded or not). The high transferability of ReaxFF makes it particularly well suited for simulations of non-equilibrium reactive dynamics at complex, heterogeneous material surfaces and interfaces.

ReaxFF has been extensively validated on numerous applications involving reaction processes, including: hydrocarbons [30], silicon/silicon oxide interfaces [41], peroxides [42], laser ablation of organic molecules on metal surfaces, recently, hydrocarbon combustion [43] (see figure 4). Furthermore, Goddard and coworkers[44] have demonstrated the parallel scalability of ReaxFF on several large-domain problems [45-47], and its current open-source implementation for LAMMPS[19, 35] (Plimpton and Thompson at Sandia National Laboratory) enables billion atom simulations under massively parallel computations.

We first tested the ability of the current ReaxFF forcefield to describe the energetics of solvated the $\mathrm{HCO}_{3}{ }^{-}$and $\mathrm{CO}_{2}$ species obtained. We use the original ReaxFF parameters for hydrocarbons[30] to describe the $\mathrm{HCO}_{3}$ - and $\mathrm{CO}_{2}$ molecules, and the recently developed ReaxFF water potential[23] for the waters. For the solvated $\mathrm{CO} 2$ species, we find excellent agreement between the QM and ReaxFF energies. 


\begin{tabular}{lrrrrr}
\hline \# $\mathrm{H}_{\mathbf{2}} \mathbf{O}$ & \multicolumn{1}{l}{ QM } & \multicolumn{2}{l}{ ReaxFF } & \multicolumn{1}{l}{ Error } & \% Error \\
\hline & & \multicolumn{3}{c}{$\mathrm{CO}_{2}$} \\
& $\mathbf{1}$ & -5.65 & -6.29 & 0.64 & 11.33 \\
& $\mathbf{2}$ & -9.36 & -8.89 & -0.47 & 5.02 \\
& $\mathbf{3}$ & -7.58 & -7.29 & -0.3 & 3.91 \\
& $\mathbf{4}$ & -12.77 & -11.93 & -0.84 & 6.57 \\
& $\mathbf{5}$ & -13.78 & -15.33 & 1.55 & 11.25 \\
& $\mathbf{6}$ & -14.62 & -14.14 & -0.48 & 3.25 \\
& $\mathbf{7}$ & -14.69 & -14.16 & -0.53 & 3.6 \\
& $\mathbf{8}$ & -13.34 & -13.14 & -0.2 & 1.48 \\
& $\mathbf{9}$ & -13.73 & -14.8 & 1.07 & 7.78 \\
& $\mathbf{1 0}$ & -13.85 & -13.63 & -0.22 & 1.57 \\
\hline Average & & & & 0.02 & 5.58 \\
StDev & & & & 0.79 & 3.59 \\
R2 & & & & 0.94 & \\
\hline
\end{tabular}

Table 3: Comparison of ReaxFF and QM energies for solvated CO2 clusters.

We find an average error of $0.02 \pm 0.8 \mathrm{kcal} / \mathrm{mol}$, and a $94 \%$ correlation.

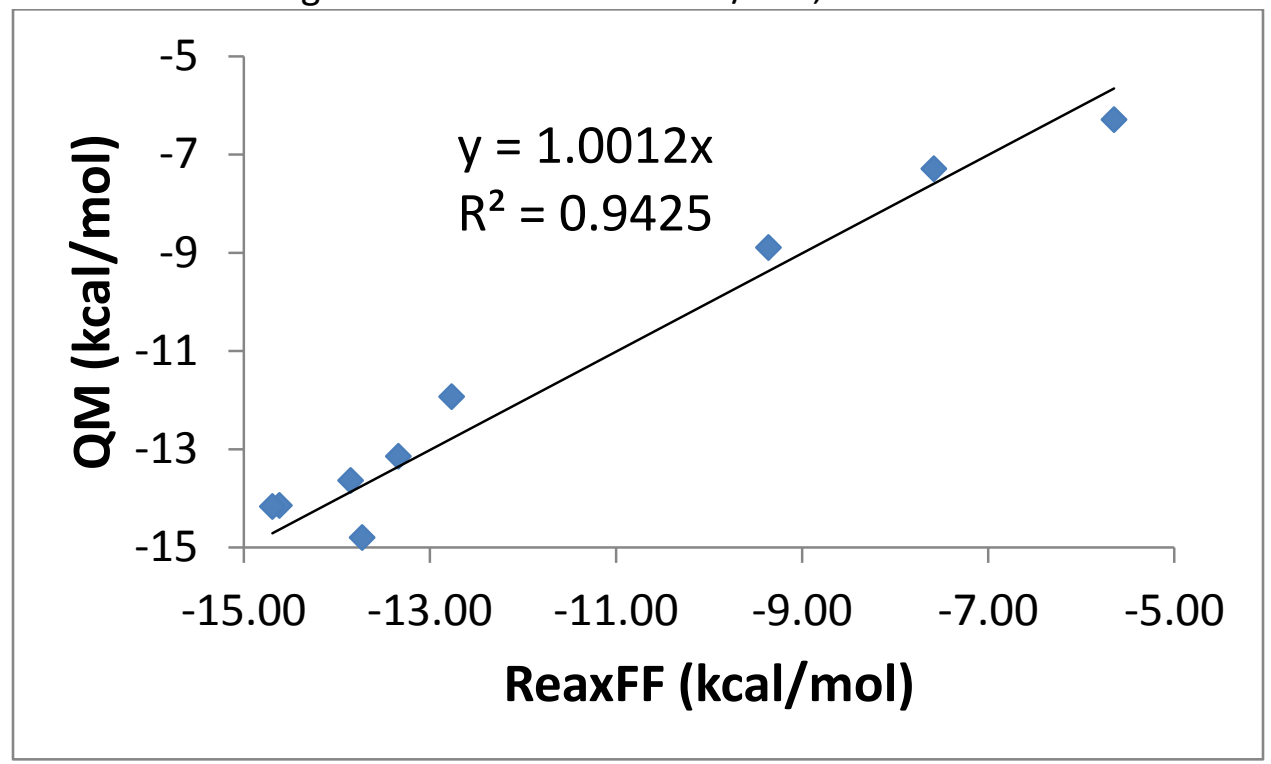

Figure 6: Correlation between ReaxFF and QM energies for solvated $\mathrm{CO}_{2}$ species

However we find that ReaxFF does not accurately describe the low lying energetic states. 


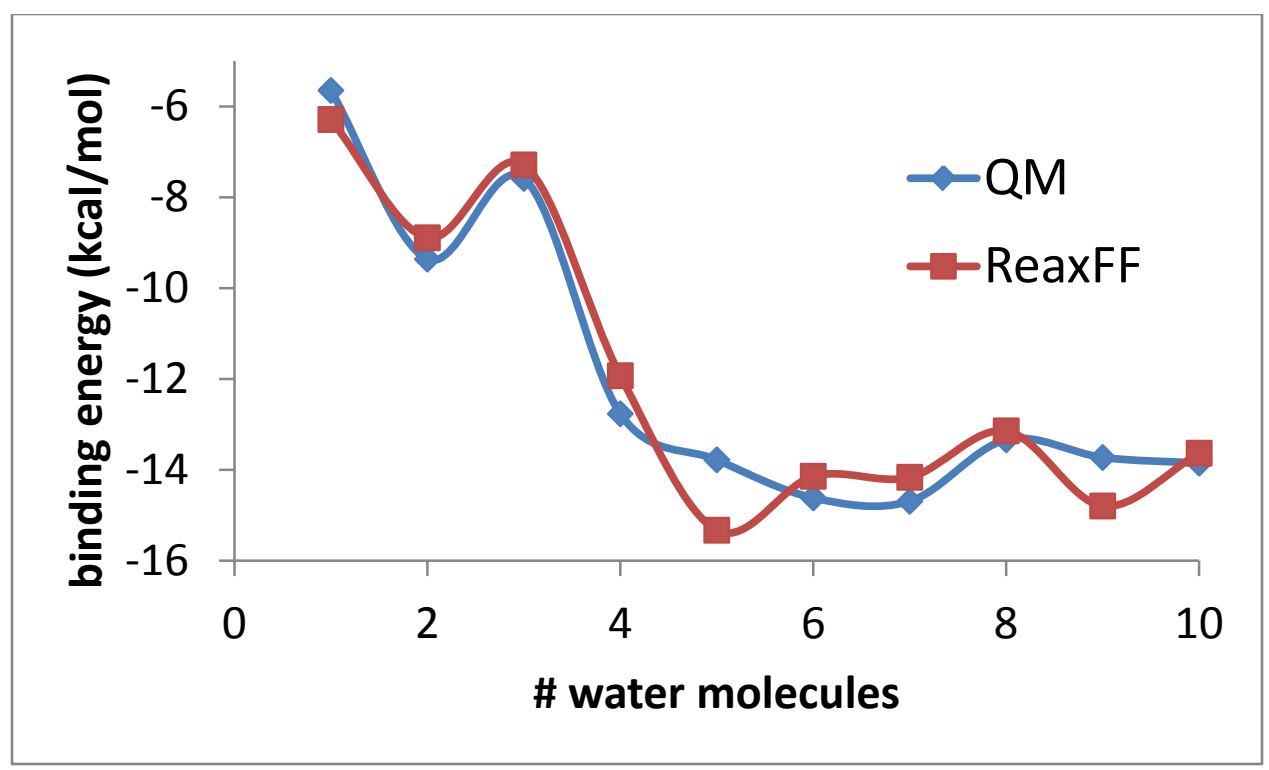

Figure 7: Binding energies of solvated $\mathrm{CO}_{2}$ structure from QM and ReaxFF

ReaxFF incorrectly predicts that the CO2 structure with 5 waters is the most stable, while the QM predicts that the structure with 6-7 waters is the most stable, although we note that these structures are within $2 \mathrm{kcal} / \mathrm{mol}$ of each other and may be difficult to differentiate even with the most accurate forcefields. We believe that the equilibrium van der Waals distances will have to be adjusted in order to obtain the correct splitting. Schemes to obtain the optimal parameters using Genetic Algorithm are currently being pursued.

In the case of the $\mathrm{HCO}_{3}$ - species, we find that ReaxFF reproduces the QM energies to within $0.8 \pm 0.6 \mathrm{kcal} / \mathrm{mol}$.

\begin{tabular}{rrrrrr}
\hline \# H2O & \multirow{2}{*}{ QM } & ReaxFF & Error & $\begin{array}{l}\text { \% } \\
\text { Error }\end{array}$ \\
& & \multicolumn{5}{c}{ HCO3- } \\
& $\mathbf{1}$ & -17.01 & -17.88 & 0.87 & 5.12 \\
& $\mathbf{2}$ & -18.49 & -18.54 & 0.05 & 0.27 \\
& $\mathbf{3}$ & -19.12 & -19.35 & 0.23 & 1.22 \\
& $\mathbf{4}$ & -19.41 & -19.79 & 0.38 & 1.95 \\
& $\mathbf{5}$ & -18.22 & -19.67 & 1.45 & 7.97 \\
& $\mathbf{6}$ & -17.72 & -18.25 & 0.53 & 2.98 \\
& $\mathbf{7}$ & -18.99 & -20.76 & 1.76 & 9.28 \\
& $\mathbf{8}$ & -17.83 & -19.42 & 1.59 & 8.89 \\
& $\mathbf{9}$ & -18.34 & -19.51 & 1.17 & 6.38 \\
& $\mathbf{1 0}$ & -16.13 & -16.22 & 0.09 & 0.59 \\
Average & & & 0.81 & 4.46 \\
StdDev & & & 0.64 & 3.51 \\
R2 & & & 0.74 & \\
\hline
\end{tabular}

Table 4: Comparison of ReaxFF and QM energies for solvated $\mathrm{HCO}_{3}{ }^{-}$clusters 
The $74 \%$ correlation is worse than in the case of the $\mathrm{CO}_{2}$ species.

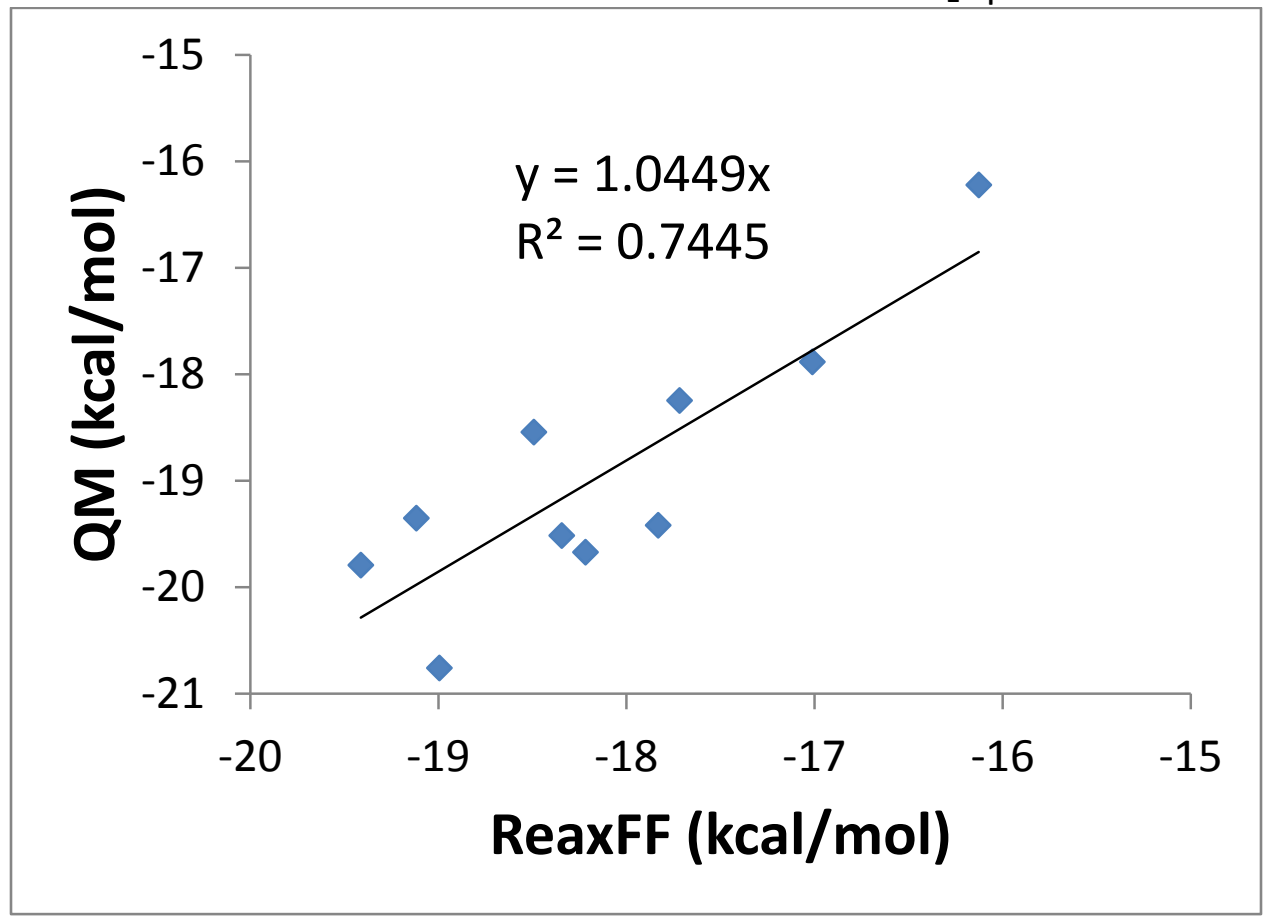

Figure 8: Correlation between ReaxFF and QM energies for solvated $\mathrm{HCO}_{3}{ }^{-}$species

Here, the largest disagreement relates to the stability of the 7 water structure, where ReaxFF predicts a global minimum while the QM predicts a local minimum.

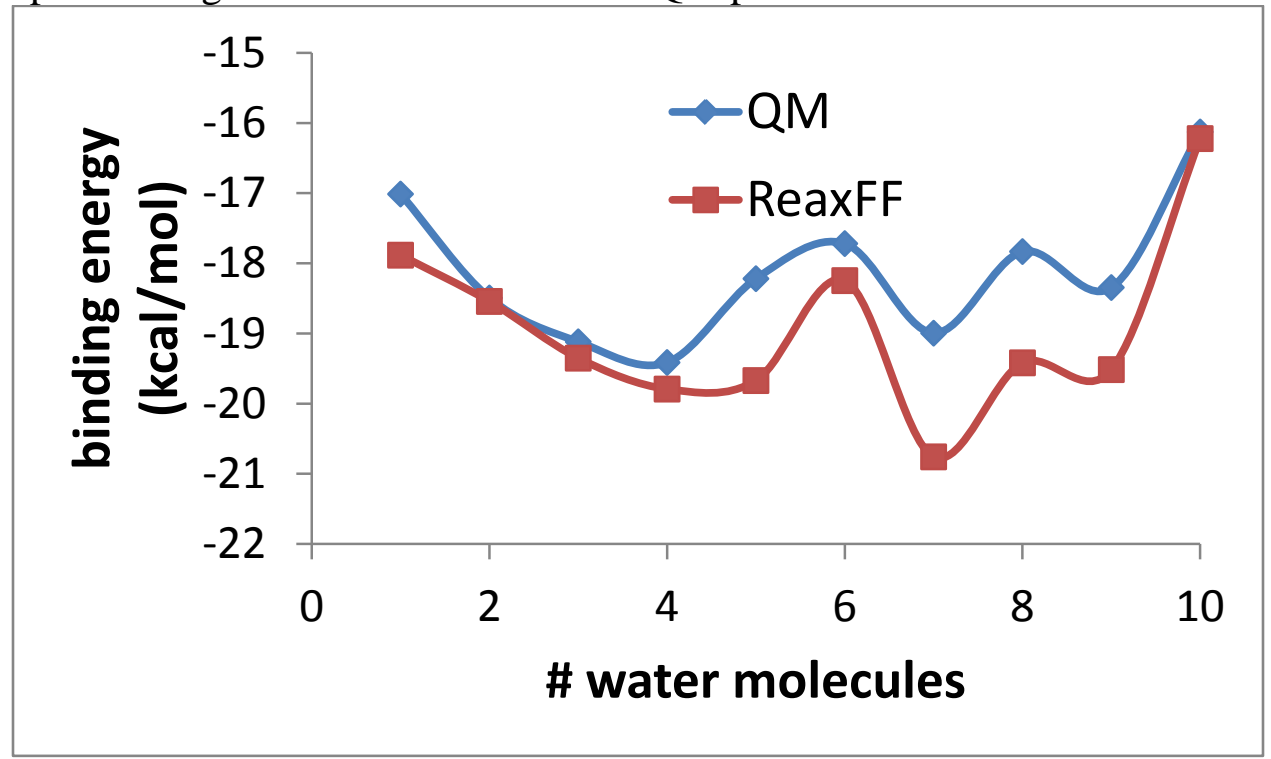

Figure 9: Binding energies of solvated $\mathrm{HCO}_{3}{ }^{-}$structure from QM and ReaxFF

Since HCO3- has a net charge, we believe that the QEq parameters used to determine the ReaxFF charges are the reason for the observed differences. We have initiated a program to obtain parameters to better reproduce the QM results in a variety of systems. It is our hope that this will resolve much of the noted discrepancies. 


\section{C.3.B. Optimization of ReaxFF to match results from QM DFT simulation}

Using our evolutionary algorithm strategy, our new forcefield (ReaxFF-DIC) gives excellent agreement to the $\mathrm{QM}$ for both the $\mathrm{CO}_{2}$ and $\mathrm{HCO}_{3}{ }^{-}$species as shown in Table 5.

\begin{tabular}{|c|c|c|c|c|c|c|c|}
\hline \multirow[t]{2}{*}{ \# $\mathrm{H}_{2} \mathrm{O}$} & \multirow[t]{2}{*}{ QM } & \multirow[t]{2}{*}{ ReaxFF } & \multicolumn{5}{|c|}{ ReaxFF-DIC } \\
\hline & & & Error & \% Error & & Error & \% Error \\
\hline \multicolumn{8}{|c|}{$\mathrm{CO}_{2}$} \\
\hline 1 & -5.65 & -6.29 & 0.64 & 11.33 & -4.81 & 0.84 & -14.81 \\
\hline 2 & -9.36 & -8.89 & -0.47 & 5.02 & -10.05 & -0.69 & 7.42 \\
\hline 3 & -7.58 & -7.29 & -0.3 & 3.91 & -7.97 & -0.39 & 5.12 \\
\hline 4 & -12.77 & -11.93 & -0.84 & 6.57 & -13.75 & -0.98 & 7.68 \\
\hline 5 & -13.78 & -15.33 & 1.55 & 11.25 & -13.12 & 0.66 & -4.81 \\
\hline 6 & -14.62 & -14.14 & -0.48 & 3.25 & -15.5 & -0.88 & 6.05 \\
\hline 7 & -14.69 & -14.16 & -0.53 & 3.6 & -14.34 & 0.35 & -2.38 \\
\hline 8 & -13.34 & -13.14 & -0.2 & 1.48 & -14.06 & -0.72 & 5.42 \\
\hline 9 & -13.73 & -14.8 & 1.07 & 7.78 & -14.64 & -0.91 & 6.63 \\
\hline 10 & -13.85 & -13.63 & -0.22 & 1.57 & -14.38 & -0.53 & 3.83 \\
\hline Average & & & 0.02 & 5.58 & & -0.33 & 2.02 \\
\hline StDev & & & 0.79 & 3.59 & & 0.65 & 6.87 \\
\hline R2 & & & 0.94 & & & 0.97 & \\
\hline \multicolumn{8}{|c|}{ HCO3- } \\
\hline 1 & -17.01 & -17.88 & 0.87 & 5.12 & -16.65 & 0.36 & -2.13 \\
\hline 2 & -18.49 & -18.54 & 0.05 & 0.27 & -18.78 & -0.29 & 1.56 \\
\hline 3 & -19.12 & -19.35 & 0.23 & 1.22 & -19.06 & 0.06 & -0.3 \\
\hline 4 & -19.41 & -19.79 & 0.38 & 1.95 & -19.09 & 0.32 & -1.66 \\
\hline 5 & -18.22 & -19.67 & 1.45 & 7.97 & -18.06 & 0.16 & -0.9 \\
\hline 6 & -17.72 & -18.25 & 0.53 & 2.98 & -17.96 & -0.24 & 1.34 \\
\hline 7 & -18.99 & -20.76 & 1.76 & 9.28 & -19.13 & -0.14 & 0.72 \\
\hline 8 & -17.83 & -19.42 & 1.59 & 8.89 & -17.53 & 0.3 & -1.68 \\
\hline 9 & -18.34 & -19.51 & 1.17 & 6.38 & -18.22 & 0.12 & -0.63 \\
\hline 10 & -16.13 & -16.22 & 0.09 & 0.59 & -16.21 & -0.08 & 0.48 \\
\hline Average & & & 0.81 & 4.46 & & 0.06 & -0.32 \\
\hline StdDev & & & 0.64 & 3.51 & & 0.22 & 1.24 \\
\hline R2 & & & 0.74 & & & 0.95 & \\
\hline
\end{tabular}

Table 5: Comparison of QM and ReaxFF (original) and ReaxFF-DIC (optimized) energies for $\mathrm{CO}_{2}$ and $\mathrm{HCO}_{3}{ }^{-}$ species coordinated with various amounts of water molecules.

Thus we have developed a new forcefield (Table 6) to reproduce all the features of the QM PES, obtaining the correct global and local minimas for the $\mathrm{HCO}_{3}{ }^{-}$structures 


\begin{tabular}{|c|c|c|c|c|c|c|c|c|}
\hline \multirow[t]{4}{*}{ C } & 1.3817 & 4. $00 \theta \Theta$ & $12 . \Theta \Theta \Theta \Theta$ & 1.8903 & 0.1838 & 0.7505 & 1.1341 & 4. 6 \\
\hline & 9.7559 & 2.1346 & 4.0000 & 34.9350 & 79.5548 & 5.0205 & 5.7084 & $\theta . \epsilon$ \\
\hline & 1.2114 & $\Theta . \theta 00 \Theta$ & 202.5551 & 8.9539 & 34.9289 & 13.5366 & 0.8563 & O.E \\
\hline & -2.8983 & $2.500 \theta$ & 1.0564 & $4.000 \Theta$ & 2.9663 & $\Theta . \Theta \Theta \Theta \Theta$ & $0.000 \theta$ & O.E \\
\hline \multirow[t]{4}{*}{$\mathrm{H}$} & 0.8855 & $1.0 \theta \theta \theta$ & 1.0080 & 1.9000 & 0.0412 & 0.6424 & $-0.100 \theta$ & $1 . \epsilon$ \\
\hline & 8.5000 & 80.7451 & 1.0000 & 0.0000 & 121.1250 & 4.6043 & 7.1825 & 1.6 \\
\hline & -0.1000 & $0.000 \theta$ & 61.6606 & 1.9908 & 3.6082 & 0.0003 & 1.0698 & O.E \\
\hline & -18.8113 & 1.6999 & 1.0338 & 1.0000 & 2.8793 & $0.000 \theta$ & $0.000 \theta$ & O.E \\
\hline \multirow[t]{4}{*}{0} & 1.2450 & $2.000 \Theta$ & 15.9990 & 2.3967 & 0.2486 & 1.1000 & 1.0548 & $6 . \epsilon$ \\
\hline & 8.5729 & 65.4233 & 4. $\Theta \theta \Theta \Theta$ & 37.5000 & 116.0768 & 8.5000 & 7.7196 & 2. $\epsilon$ \\
\hline & 0.9049 & 8.5473 & 59.0626 & 2.5529 & 0.9643 & 0.0021 & 0.9745 & $\theta . \epsilon$ \\
\hline & -3.7080 & 5.7560 & 1.0493 & 4.0000 & 2.9225 & 0.0000 & $\theta . \theta 0 \theta \theta$ & $\theta . \epsilon$ \\
\hline \multirow[t]{4}{*}{$\mathrm{C}$} & 1.3763 & 4. 0000 & 12.0000 & 1.8857 & 0.1818 & 0.8712 & 1.2596 & 4. 6 \\
\hline & 9.5928 & 2.0784 & 4. $\Theta \Theta \Theta \Theta$ & 22.6732 & 79.5548 & 5.7254 & 6.9235 & $\theta . \epsilon$ \\
\hline & 1.2065 & 0.0000 & -0.8579 & 4.9417 & 28.3475 & 11.9957 & 0.8563 & $\theta . \epsilon$ \\
\hline & -2.8846 & 4.1590 & 1.0564 & $4.000 \Theta$ & 2.9663 & $0.000 \theta$ & $\theta .00 \theta \Theta$ & O.C \\
\hline \multirow[t]{4}{*}{ H } & 0.6646 & $1 . \theta \theta \theta \theta$ & 1.0080 & 1.6030 & 0.0600 & 0.7625 & -0.1000 & 1.e \\
\hline & 9.3951 & 4.4187 & 1.0000 & 0.0000 & 121.1250 & 3.8196 & 9.8832 & $1 . \epsilon$ \\
\hline & -0.1000 & $\theta . \theta \Theta \theta \Theta$ & -0.1339 & 3.5803 & 2.8733 & $1 . \theta \Theta \Theta \theta$ & 1.0698 & O.E \\
\hline & -13.0615 & 3.0626 & 1.0338 & 1. $00 \theta \Theta$ & 2.8793 & $\theta .00 \theta \theta$ & $\theta . \theta 0 \theta \theta$ & $\theta . \epsilon$ \\
\hline \multirow[t]{4}{*}{0} & 1.2699 & $2.000 \theta$ & 15.9990 & 1.9741 & 0.0880 & 1.0804 & 1.0624 & 6.6 \\
\hline & 10.2186 & 7.7719 & 4.0000 & 27.3264 & 116.0768 & 8.5000 & 7.8386 & $2 . \epsilon$ \\
\hline & 0.9446 & 8.6170 & -1.2371 & 17.0845 & 3.7082 & 0.5350 & 0.9745 & $\theta . \epsilon$ \\
\hline & -3.1456 & 2.6656 & 1.0493 & $4.000 \Theta$ & 2.9225 & $\Theta . \theta \Theta \Theta \Theta$ & $\theta . \theta 0 \theta \Theta$ & $\theta . \epsilon$ \\
\hline
\end{tabular}

Table 6: Comparison of ReaxFF-DIC (top) C,H and O parameters to the original ReaxFF hydrocarbon (bottom) parameters. Our evolutionary algorithm optimization routine resulted in only minor perturbations to the parameter, but significant improvements in describing the solvation potential energy surface of $\mathrm{HCO}_{3}{ }^{-}$/water structures.

\section{C.3.C. ReaxFF simulation for DIC Mid-IR spectra under high pressure and temperature}

As shown in figure 10, the relative populations (stability) of $\mathrm{HCO} 3-$ and $\mathrm{CO} 2$ in water are a dramatic function of the temperature and pressure. At room temperature and $1 \mathrm{GPa}$, on average of 2 $\mathrm{CO} 2$ molecules react with water to produce $\mathrm{HCO} 3-$ and $\mathrm{H} 3 \mathrm{O}+$. This slightly acidifies the solution, although the level of acidification would be related to the concentration of each species. The concentrations used in this study were purposefully higher than should be realistically expected so as to model the extreme conditions. 


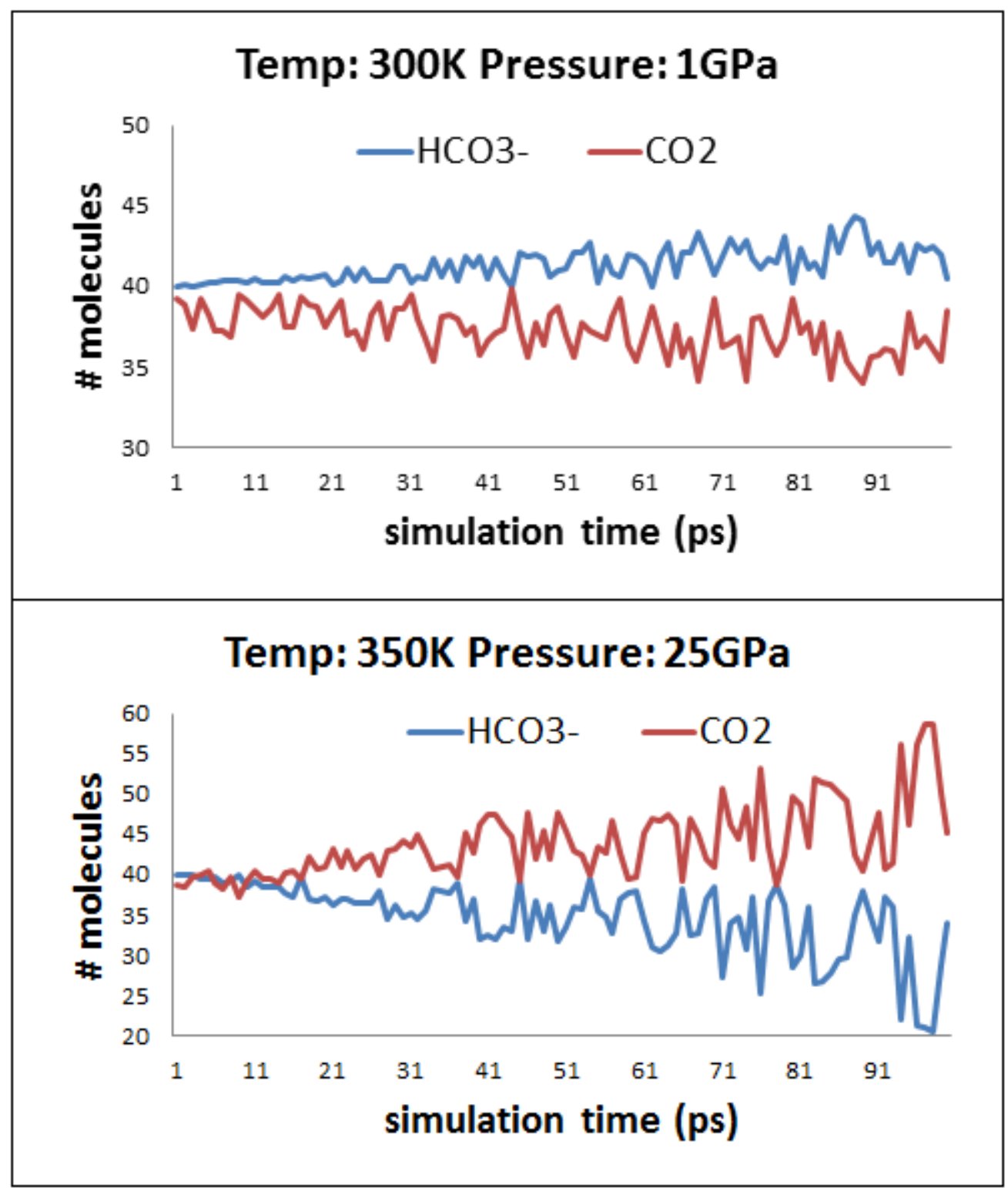

Figure 10: Time evolution of the number of $\mathrm{CO}_{2}\left(\mathrm{as}_{2} \mathrm{CO}_{3}\right)$ and $\mathrm{HCO}_{3}{ }^{-}$species during reactive molecular dynamics. At room temperature and $1 \mathrm{GPa}$, the $\mathrm{HCO}_{3}{ }^{-}$species is stabilized, with $2 \mathrm{CO}_{2}$ molecules reacting with water to produce $\mathrm{HCO}_{3}{ }^{-}$and a hydronium ion. However, at high temperature and pressure, the $\mathrm{CO}_{2}$ species is stabilized, with up to $10 \mathrm{HCO}_{3}{ }^{-}$ions reacting with water.

We note that the $\mathrm{HCO}_{3}{ }^{-} / \mathrm{CO}_{2}$ species exists in equilibrium, with frequent production and consumption of each during dynamics. While there is a definite trend towards the consumption of $2 \mathrm{CO}_{2}$ to form $\mathrm{HCO}_{3}{ }^{-}$over the $100 \mathrm{ps}$, we find at least 2 cases where the population of $\mathrm{CO}_{2}$ is actually higher than $\mathrm{HCO}_{3}{ }^{-}$. This indicates a thermodynamic equilibrium that may be quantitatively described using the Two-Phase thermodynamics model $[9,10]$ recently developed at Caltech.

At higher temperature and pressures, the equilibrium shifts towards formation of $\mathrm{CO}_{2}$, with an average of $7 \mathrm{HCO}_{3}{ }^{-}$ions reacting with water (or hydronium ions) to form $\mathrm{H}_{2} \mathrm{CO}_{3}$. The depletion of hydronium ions would indicate that the solutions would become more basic over time. 


\section{C.3.D. Hydration environment around $\mathrm{CO}_{2}$ and $\mathrm{HCO}_{3}{ }^{-}$}

We calculate the number of neighbours in the $1^{\text {st }}$ solvation shell around each CO2 molecule in figure 11 . We find that the predominant number of $1^{\text {st }}$ shell neighbours is 18 .

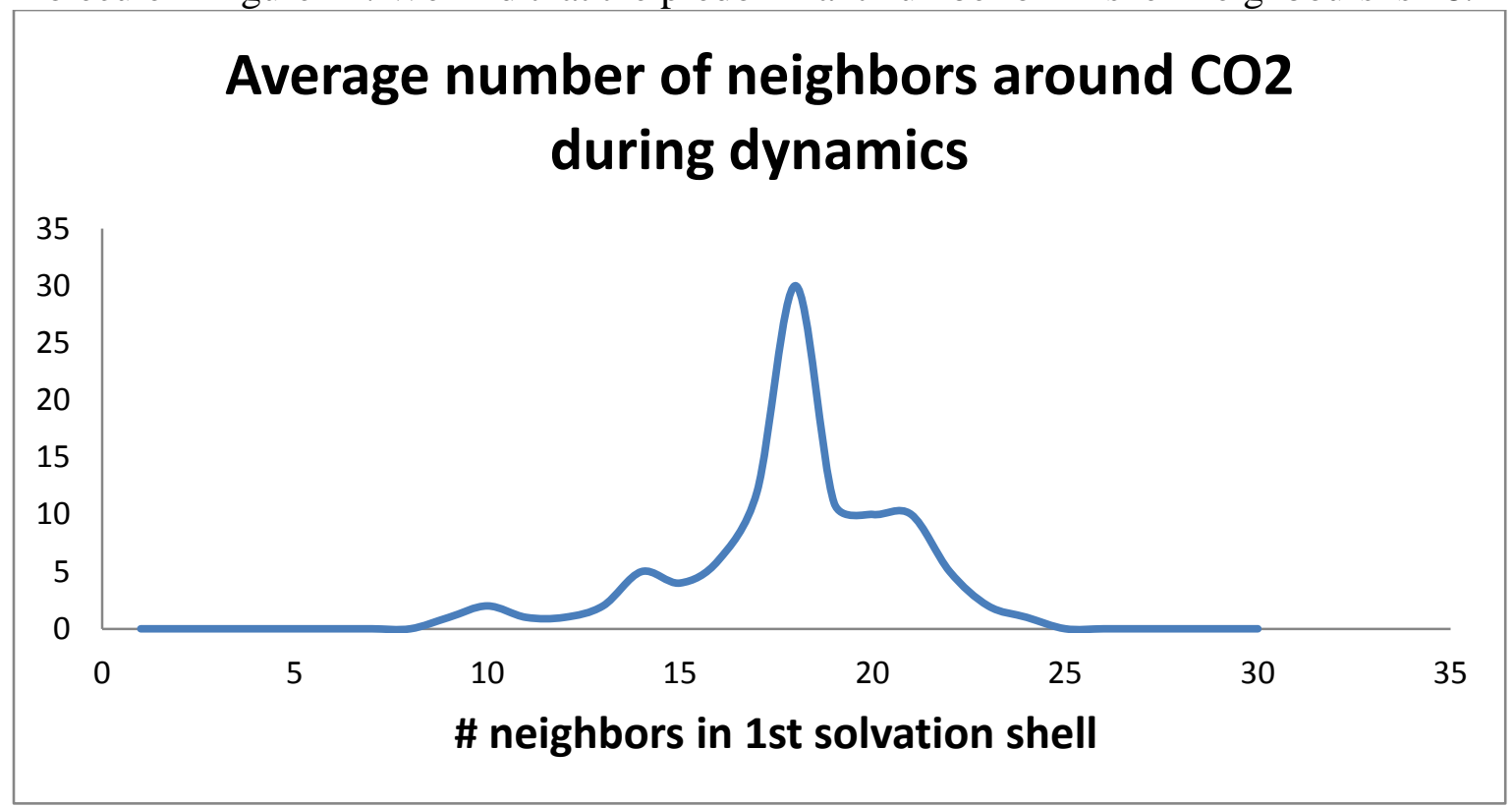

Figure 11: Number of $1^{\text {st }}$ shell neighbors around hydrated $\mathrm{CO}_{2}$ at $300 \mathrm{~K}$ and 1 atm

We took 189 representative structure of $\mathrm{CO}_{2}\left(\mathrm{H}_{2} \mathrm{O}\right)_{18}$ and performed QM energy single point energy calculations at the X3LYP/6-31G** level of Density Functional Theory. The most stable structure is a clathrate-like cage structure shown in figure 12. We calculate a hydration free energy of $0.45 \mathrm{kcal} / \mathrm{mol}$, in good agreement with the experimental value of $0.18 \mathrm{kcal} / \mathrm{mol}$. 


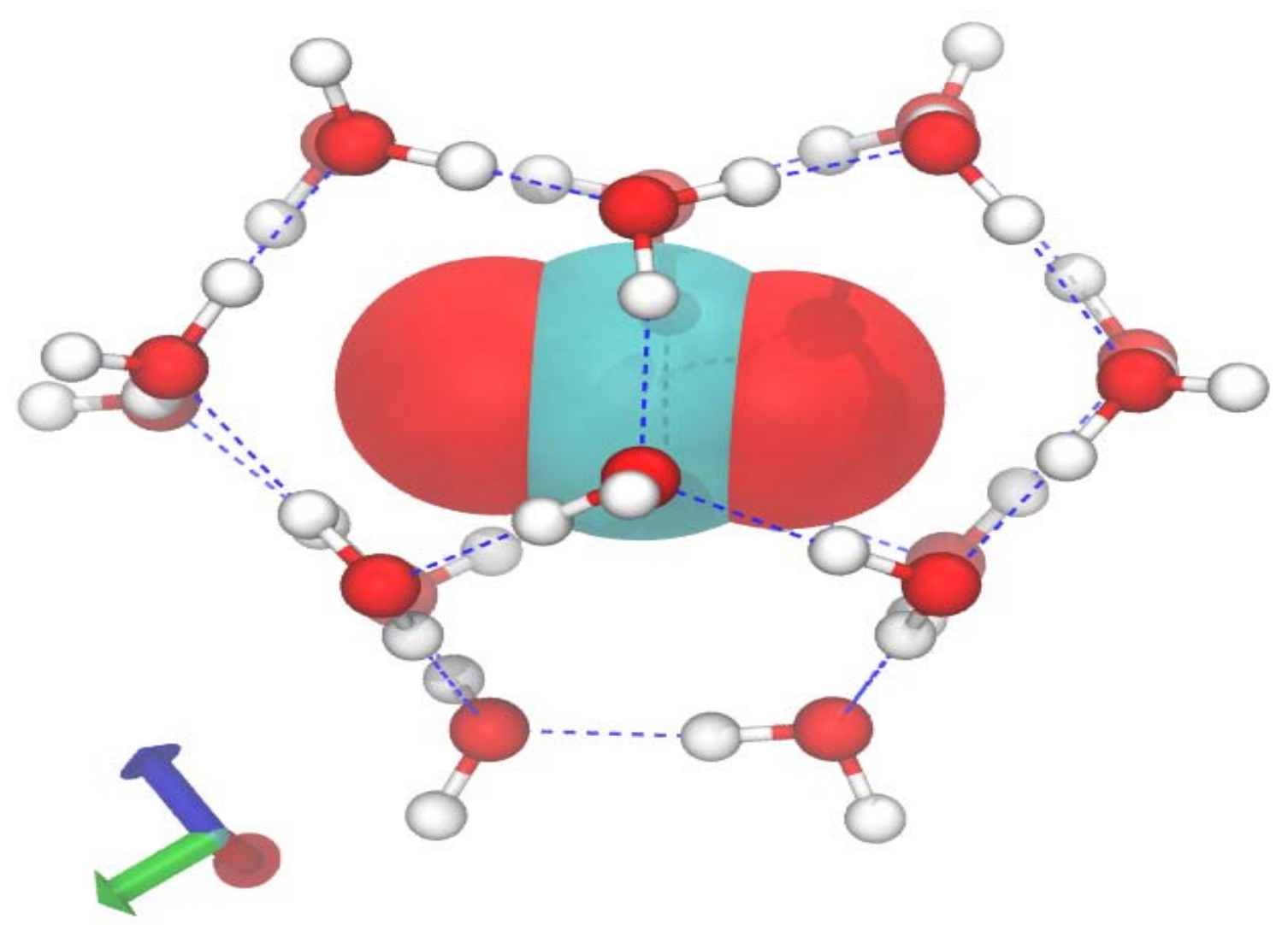

Figure 12: Most stable $\mathrm{CO}_{2}\left(\mathrm{H}_{2} \mathrm{O}\right)_{18}$ structure from QM single point energy calculations

In contrast and as shown in figure 12, the solvation environment around HCO3- contains between $22-23$ waters. We found that 12 of the configurations were degenerate in energy (within $1 \mathrm{kcal} / \mathrm{mol}$ of each other which is within the accuracy of this level of theory).

\section{Average number of neighbors around HCO3- during dynamics}

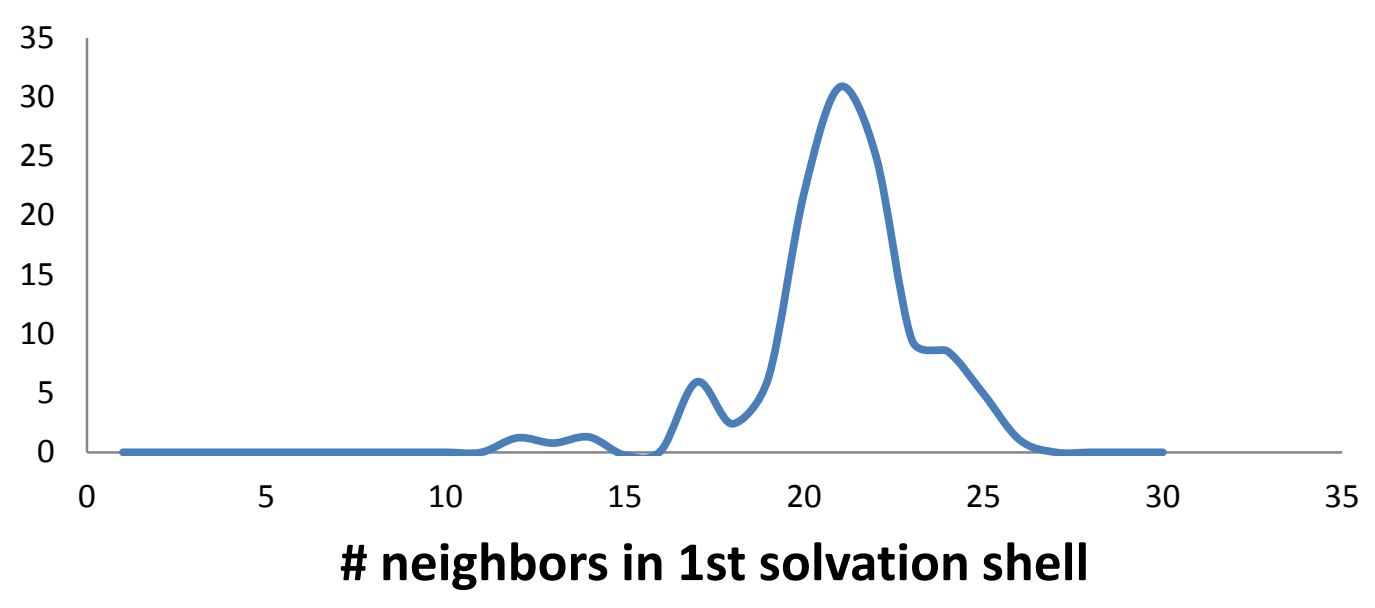

Figure 12: Number of $1^{\text {st }}$ shell neighbours around hydrated $\mathrm{HCO}_{3}{ }^{-}$at $300 \mathrm{~K}$ and 1 atm 


\section{C.3.E. IR spectra of DICs under various temperature and pressure conditions}

Using our proposed approach from linear response theory detailed above, we simulated gaseous $\mathrm{CO} 2$ and calculated the spectra and compared to experimental measurements. As shown in table 7, we find excellent agreement with experiments and high level QM calculation that explicitly calculate the electronic dipole transition matrix elements:

\begin{tabular}{|l|r|r|rr|}
\hline $\begin{array}{l}\text { Experimental Peak frequency } \\
\left(\mathbf{c m}^{-1}\right)\end{array}$ & $\mathbf{5 4 0}$ & $\mathbf{1 2 6 0}$ & $\mathbf{1 5 8 8}$ \\
\hline Assignment & $\begin{array}{l}\text { C-O } \\
\text { bending }\end{array}$ & $\begin{array}{l}\text { C-O symmetric } \\
\text { stretch }\end{array}$ & $\begin{array}{l}\text { C-O asymmetric } \\
\text { stretch }\end{array}$ \\
\hline QM/X3LYP/^-31G** & 538 & 1255 & 1590 \\
\hline $\begin{array}{l}\text { Reax-DIC/linear response } \\
\text { theory }\end{array}$ & 539 & 1247 & 1583 \\
\hline
\end{tabular}

Table 7: Comparison of gas phase $\mathrm{CO} 2$ frequencies from experiments, QM calculations and ReaxDIC/Linear response theory simulations

Having verified that our method accurately reproduces the CO2 IR spectra, we calculated the spectra under three temperature/pressure conditions:

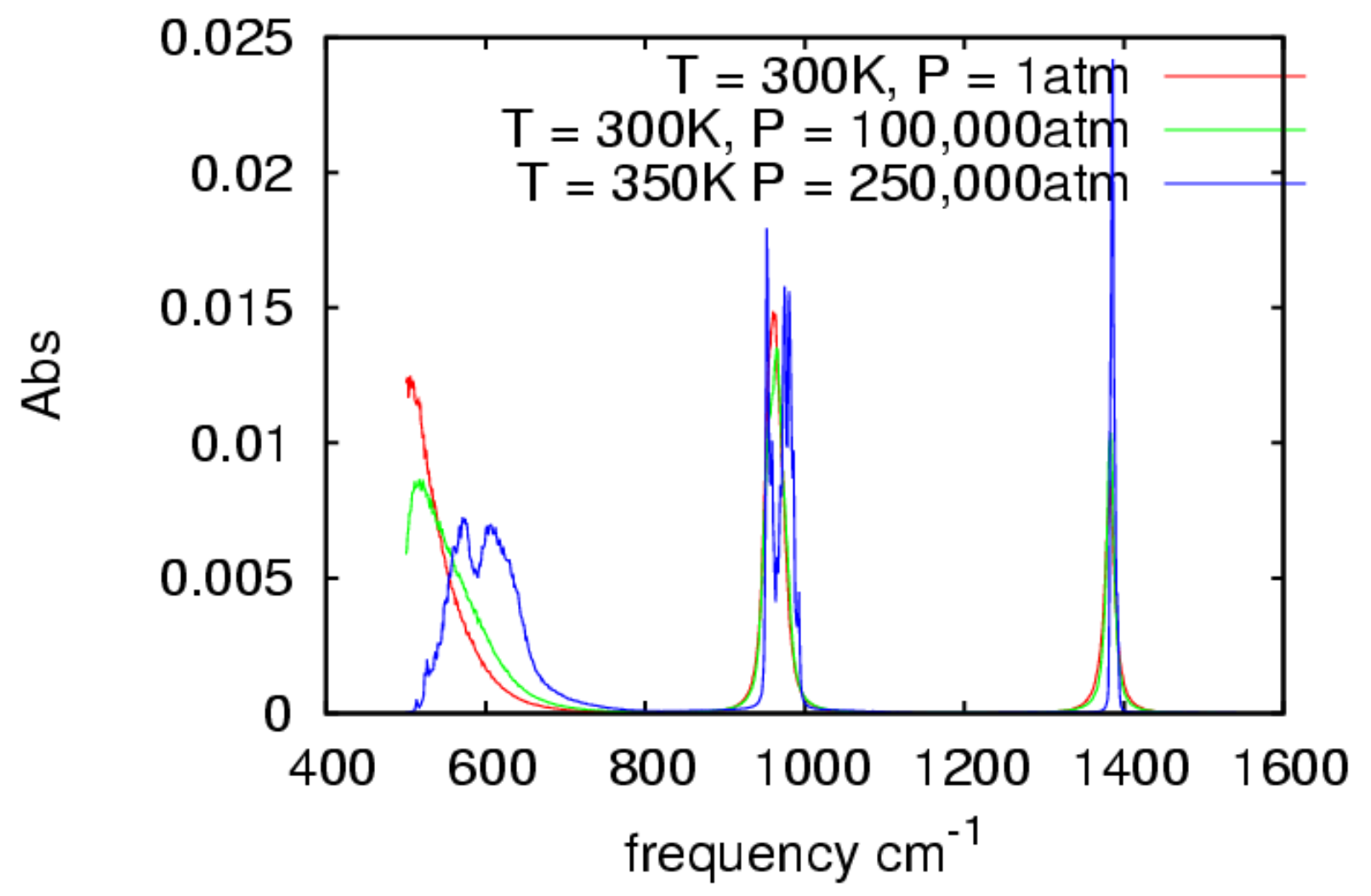

Figure 13: Comparison of the IR spectra of DICs under three temperature and pressure conditions.

We find that the hydrated spectra display several distinct features:

1. blue shifting of the $\mathrm{C}-\mathrm{O}$ stretching bands by as much as 50 wavenumbers at $300 \mathrm{~K}$ and $1 \mathrm{~atm}$ 
2. splitting of the $\mathrm{C}-\mathrm{O}$ bending mode at high pressure and temperature, indicative of distinct solvation environments. Alternatively, this could be indicative of the 3-fold degenerate bending modes of $\mathrm{CO}_{3}{ }^{2-}$ ion.

3. splitting of the C-O symmetric stretching mode at high pressure and temperature

\section{C.4.A. ReaxFF simulation of high salinity water}

We use the ReaxFF-DIC reactive forcefield developed in task 3.1 and the standard sodium and chlorine parameters used previously[27, 30] to simulate the following systems

\begin{tabular}{|c|c|c|c|c|}
\hline & \# water & $\# \mathrm{NaCl}$ & $\begin{array}{l}\text { Temp } \\
\text { (K) }\end{array}$ & $\begin{array}{l}\text { Press } \\
\text { (GPa) }\end{array}$ \\
\hline Pure & 550 & 0 & 350 & 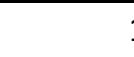 \\
\hline Brackish & 550 & 5 & 350 & 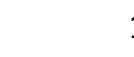 \\
\hline Brine & 550 & 50 & 350 & . \\
\hline
\end{tabular}

Table 8: Description of system used for ReaxFF simulations.

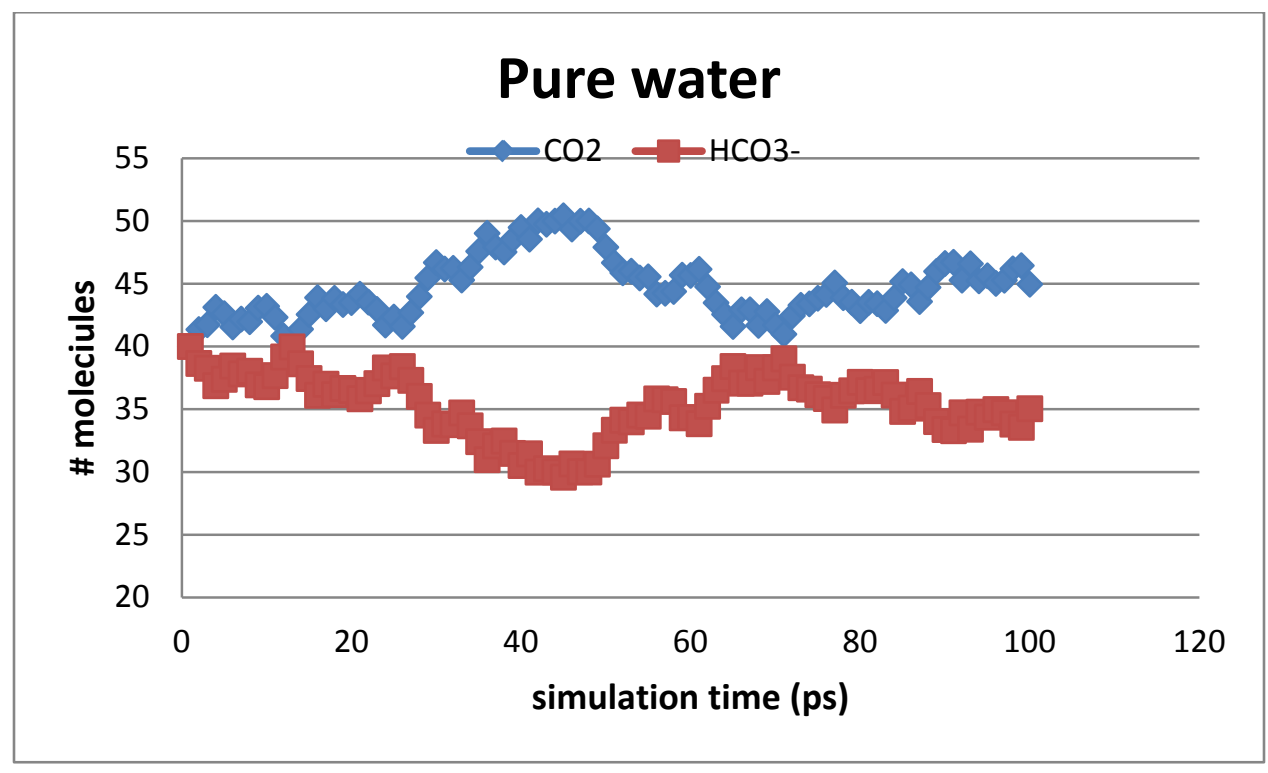




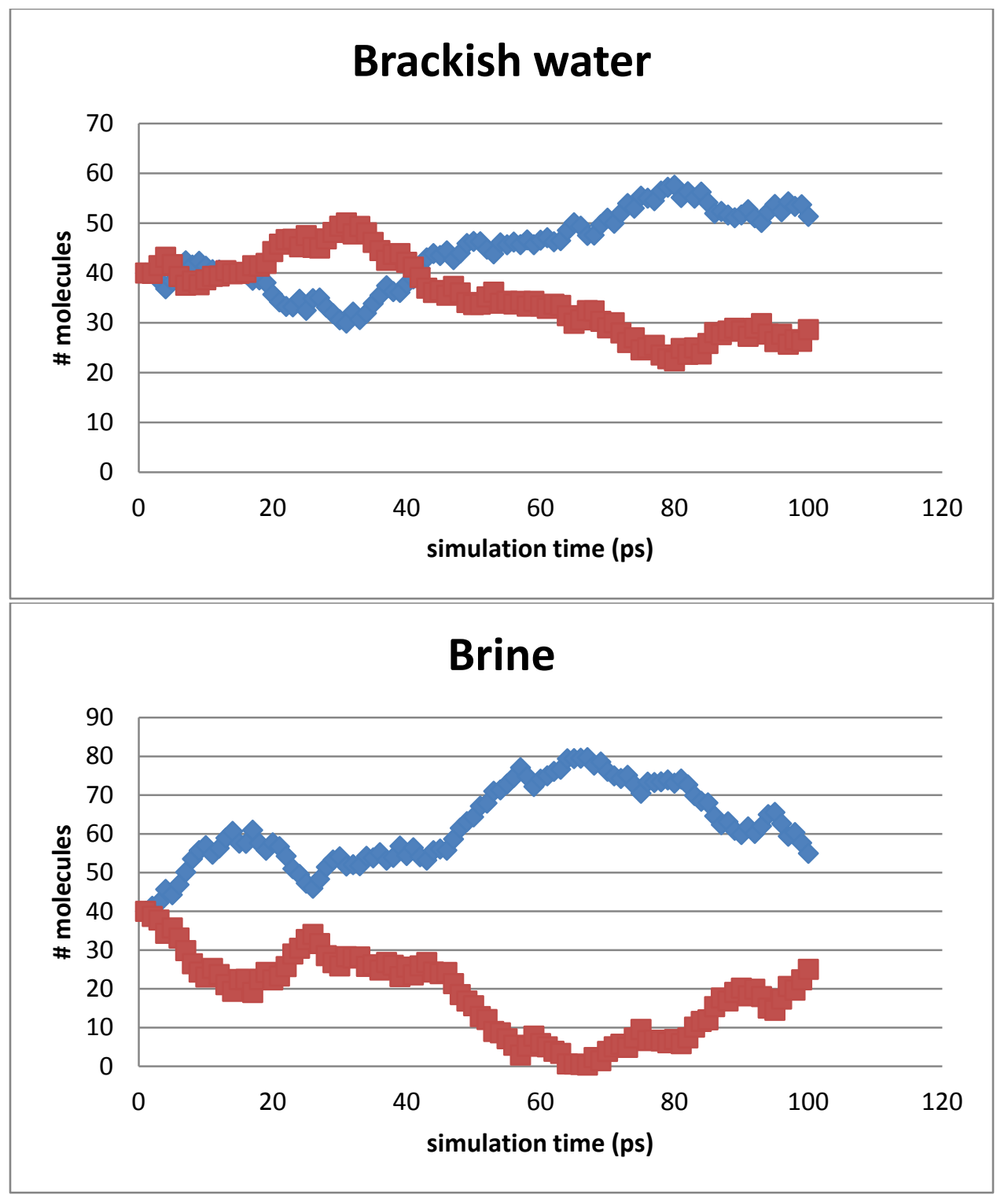

Figure 14: Time evolution of $\mathrm{CO}_{2} / \mathrm{HCO}_{3}{ }^{-}$during reactive dynamics under pure water, brackish water and brine conditions at $350 \mathrm{~K}$ and $1 \mathrm{GPa}$. The CO2 species is stabilized with increasing salt concentration.

\section{C.4.B. Thermodynamic Stability of DIC in water/brine}

\begin{tabular}{llllr}
\hline Species & $\Delta \mathrm{G}(\mathrm{kcal} / \mathrm{mol})$ & $\Delta \mathrm{H}(\mathrm{kcal} / \mathrm{mol})$ & $\mathrm{T} \Delta \mathrm{S}(\mathrm{kcal} / \mathrm{mol})$ & Rel. Equil Const. \\
\hline $\mathrm{CO}_{2}$ & $-43.23 \pm 1.67$ & $-30.81 \pm 1.24$ & $12.42 \pm 3.52$ & 0.25 \\
$\mathrm{HCO}_{3}{ }^{-}$ & $-45.52 \pm 1.34$ & $-31.29 \pm 2.45$ & $14.23 \pm 1.74$ & 0.26 \\
$\mathrm{H}_{2} \mathrm{CO}_{3}$ & $-42.23 \pm 2.46$ & $-30.21 \pm 1.98$ & $12.02 \pm 1.32$ & 0.24 \\
$\mathrm{CO}_{3}{ }^{2-}$ & $-43.10 \pm 1.92$ & $-32.63 \pm 2.12$ & $10.47 \pm 2.99$ & 0.25 \\
\hline
\end{tabular}

Table 9: Thermodynamics of DIC in $5 \%$ brine at 25GPa and 350K.

As shown in table 9, the $\mathrm{HCO}_{3}{ }^{-}$species is the most stable at this temperature and pressure owing to an increase in entropy, relative to $\mathrm{CO}_{2}$. We find that the "clathrate-like" structure 
formed by $\mathrm{CO}_{2}$ is incommensurate with the $\mathrm{HCO}_{3}{ }^{-}$ion, meaning that the waters are randomly orientated around $\mathrm{HCO}_{3}{ }^{-}$, increasing their entropy. The additional electrostatic interactions also stabilize the $\mathrm{HCO}_{3}{ }^{-}$ion. Taken together, we predict that $55-60 \%$ of dissolved $\mathrm{CO}_{2}$ to be in the $\mathrm{HCO}_{3}{ }^{-}$form

\section{C.5. DIC species' MIR spectra under high salinity conditions}

In figure 15, we present the spectra of $\mathrm{CO} 2$ in 5\% brine as a function of temperature and pressure. We find a blue shifting of the vibration frequencies with increasing pressure as the intermolecular interactions increase. Indeed, the C-O stretching mode is blue shifted by $30 \mathrm{~cm}^{-1}$ from $1 \mathrm{~atm}$ to $1 \mathrm{GPa}$ and should be measurable experimentally. There is an even greater $50 \mathrm{~cm}^{-1}$ blue shift in the O-C-O bending mode. Additionally, at high pressure (1GPa) we find a breaking of the degeneracy of the O-C-O symmetric and asymmetric modes, with a splitting of $75 \mathrm{~cm}^{-1}$. The breaking of this degeneracy is even more pronounced at higher pressures, increasing to $100 \mathrm{~cm}^{-1}$ at $400 \mathrm{~K}$. Finally, there appears to be very high frequency mode at $1400 \mathrm{~cm}-1$ that we assign to $\mathrm{H}_{2} \mathrm{O}-\mathrm{CO}_{2}$ interaction. Unsurprisingly, this mode is suppressed at higher pressures.

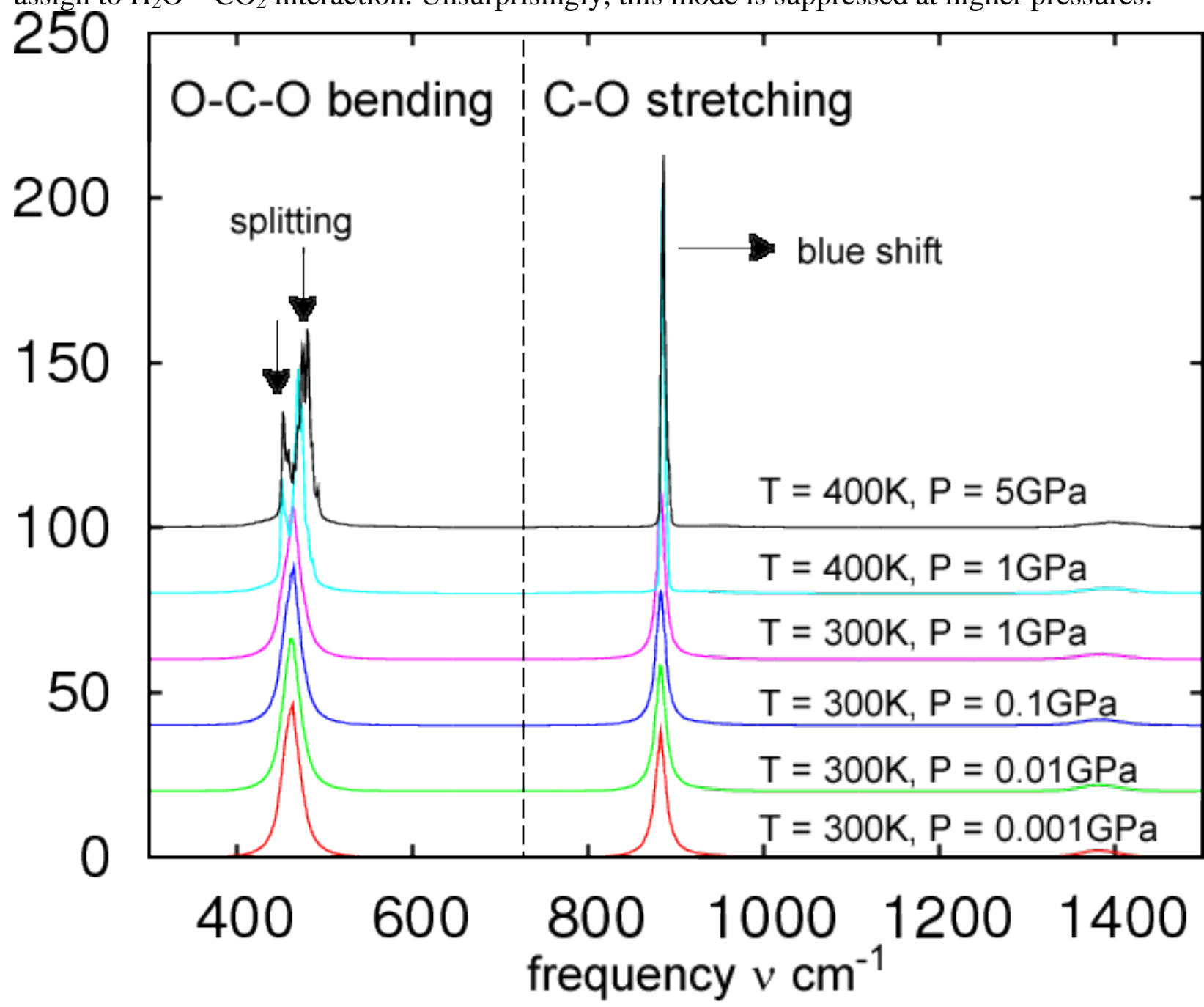

Figure 15: IR spectra of $\mathrm{CO} 2$ in $5 \%$ brine as a function of temperature and pressure. 


\section{Conclusions:}

First principles simulations of DICs in brine conditions were performed using a highly optimized ReaxFF-DIC forcefield. The thermodynamics stability of each species were determined using the 2PT method, and shown to be consistent with the Reax simulations. More importantly, we have presented the IR spectra of DIC in real brine conditions as a function of temperature and pressure. At near earth conditions, we find a breaking of the $\mathrm{O}-\mathrm{C}-\mathrm{O}$ bending modes into asymmetric and symmetric modes, separated by $100 \mathrm{~cm}-1$ at $400 \mathrm{~K}$ and $5 \mathrm{GPa}$. These results can now be used to calibrate FTIR laser measurements.

\section{E. REFERENCES:}

1. Fukushi, K. and K. Hiiro, Determination of Total Carbon-Dioxide in Seawater by Capillary Type Isotachophoresis. Fresenius Zeitschrift Fur Analytische Chemie, 1987. 328(3): p. 247-250.

2. Schumacher, T.E. and A.J.M. Smucker, Measurement of Co2 Dissolved in Aqueous-Solutions Using a Modified Infrared Gas Analyzer System. Plant Physiology, 1983. 72(1): p. 212-214.

3. Ljunggren, E. and B. Karlberg, Determination of Total Carbon-Dioxide in Beer and Soft Drinks by Gas-Diffusion and Flow-Injection Analysis. Journal of Automatic Chemistry, 1995. 17(3): p. 105108.

4. Almeida, F.V., J.R. Guimarares, and W.F. Jardim, Measuring the CO2 flux at the air/water interface in lakes using flow injection analysis. Journal of Environmental Monitoring, 2001. 3(3): p. 317-321.

5. Kolhed, M., et al., Assessment of quantum cascade lasers as mid infrared light sources for measurement of aqueous samples. Vibrational Spectroscopy, 2002. 29(1-2): p. 283-289.

6. Lyakh, A., et al., 1.6 Whigh wall plug efficiency, continuous-wave room temperature quantum cascade laser emitting at 4.6 mu m. Applied Physics Letters, 2008. 92(11).

7. Nguyen, M.T., et al., How many water molecules are actively involved in the neutral hydration of carbon dioxide? Journal of Physical Chemistry A, 1997. 101(40): p. 7379-7388.

8. Kumar, P.P., A.G. Kalinichev, and R.J. Kirkpatrick, Hydrogen-Bonding Structure and Dynamics of Aqueous Carbonate Species from Car-Parrinello Molecular Dynamics Simulations. Journal of Physical Chemistry B, 2009. 113(3): p. 794-802.

9. Pascal, T.A., S.T. Lin, and W.A. Goddard, 3rd, Thermodynamics of liquids: standard molar entropies and heat capacities of common solvents from 2PT molecular dynamics. Phys Chem Chem Phys, 2011. 13(1): p. 169-81.

10. Lin, S.T., P.K. Maiti, and W.A. Goddard, Two-Phase Thermodynamic Model for Efficient and Accurate Absolute Entropy of Water from Molecular Dynamics Simulations. Journal of Physical Chemistry B, 2010. 114(24): p. 8191-8198.

11. Lin, S.T., M. Blanco, and W.A. Goddard, The two-phase model for calculating thermodynamic properties of liquids from molecular dynamics: Validation for the phase diagram of LennardJones fluids. Journal of Chemical Physics, 2003. 119(22): p. 11792-11805.

12. Spanu, L., et al., Stability of hydrocarbons at deep Earth pressures and temperatures. Proceedings of the National Academy of Sciences, 2011. 108(17): p. 6843-6846.

13. Berens, P.H. and K.R. Wilson, MOLECULAR-DYNAMICS AND SPECTRA .1. DIATOMIC ROTATION AND VIBRATION. Journal of Chemical Physics, 1981. 74(9): p. 4872-4882.

14. Shinoda, W., M. Shiga, and M. Mikami, Rapid estimation of elastic constants by molecular dynamics simulation under constant stress. Physical Review B, 2004. 69(13): p. -. 
15. Martyna, G.J., D.J. Tobias, and M.L. Klein, Constant-Pressure Molecular-Dynamics Algorithms. Journal of Chemical Physics, 1994. 101(5): p. 4177-4189.

16. Parrinello, M. and A. Rahman, Polymorphic Transitions in Single-Crystals - a New MolecularDynamics Method. Journal of Applied Physics, 1981. 52(12): p. 7182-7190.

17. Tuckerman, M.E., et al., A Liouville-operator derived. measure-preserving integrator for molecular dynamics simulations in the isothermal-isobaric ensemble. Journal of Physics aMathematical and General, 2006. 39(19): p. 5629-5651.

18. Hockney, R.W. and J.W. Eastwood, Computer Simulation Using Particles. 1989, New York: Taylor \& Francis.

19. Plimpton, S.J., R. Pollock, and M. Stevens. Particle-Mesh Ewald and rRESPA for Parallel Molecular Dynamics Simulations. in Proc of the Eighth SIAM Conference on Parallel Processing for Scientific Computing. 1997. Minneapolis, MN

20. Courcot, B. and A.J. Bridgeman, Optimization of a Molecular Mechanics Force Field for Type-II Polyoxometalates Focussing on Electrostatic Interactions: A Case Study. Journal of Computational Chemistry, 2011. 32(8): p. 1703-1710.

21. Mueller, J.E., A.C.T. van Duin, and W.A. Goddard, Application of the ReaxFF Reactive Force Field to Reactive Dynamics of Hydrocarbon Chemisorption and Decomposition. Journal of Physical Chemistry C, 2010. 114(12): p. 5675-5685.

22. Mueller, J.E., A.C.T. van Duin, and W.A. Goddard, Development and Validation of ReaxFF Reactive Force Field for Hydrocarbon Chemistry Catalyzed by Nickel. Journal of Physical Chemistry C, 2010. 114(11): p. 4939-4949.

23. Raymand, D., et al., Water adsorption on stepped ZnO surfaces from MD simulation. Surface Science, 2010. 604(9-10): p. 741-752.

24. Goddard, W.A., et al., Multi-paradigm multi-scale simulations for fuel cell catalysts and membranes. Molecular Simulation, 2006. 32(3-4): p. 251-268.

25. Goddard, W.A., et al., Development of the ReaxFF reactive force field for mechanistic studies of catalytic selective oxidation processes on BiMoOx. Topics in Catalysis, 2006. 38(1-3): p. 93-103.

26. Strachan, A., et al., Thermal decomposition of RDX from reactive molecular dynamics. Journal of Chemical Physics, 2005. 122(5): p. -.

27. Han, S.S., et al., Optimization and application of lithium parameters for the reactive force field, ReaxFF. Journal of Physical Chemistry A, 2005. 109(20): p. 4575-4582.

28. Cheung, S., et al., ReaxFF $(\mathrm{MgH})$ reactive force field for magnesium hydride systems. Journal of Physical Chemistry A, 2005. 109(5): p. 851-859.

29. Chenoweth, K., et al., Simulations on the thermal decomposition of a poly(dimethylsiloxane) polymer using the ReaxFF reactive force field. Journal of the American Chemical Society, 2005. 127(19): p. 7192-7202.

30. van Duin, A.C.T., et al., ReaxFF: A reactive force field for hydrocarbons. Journal of Physical Chemistry A, 2001. 105(41): p. 9396-9409.

31. Eyring, H., Physical chemistry : an advanced treatise. 1967, New York; London [etc.]: Academic Press.

32. McQuarrie, D.A., Statistical mechanics. 2000, Sausalito (Calif.): University Science Books.

33. Brigham, E.O., The fast Fourier transform. 1974, Englewood Cliffs, N.J.: Prentice-Hall.

34. Mayo, S.L., B.D. Olafson, and W.A. Goddard, Dreiding - a Generic Force-Field for Molecular Simulations. Journal of Physical Chemistry, 1990. 94(26): p. 8897-8909.

35. Plimpton, S., FAST PARALLEL ALGORITHMS FOR SHORT-RANGE MOLECULAR-DYNAMICS. Journal of Computational Physics, 1995. 117(1): p. 1-19.

36. Jaguar, version 7.0, 2007, Schrödinger: New York, NY. 
37. $\mathrm{Xu}, \mathrm{X}$. and W.A. Goddard, The X3LYP extended density functional for accurate descriptions of nonbond interactions, spin states, and thermochemical properties. Proceedings of the National Academy of Sciences of the United States of America, 2004. 101(9): p. 2673-2677.

38. Hehre, W.J.R., L.; Schleyer, P. v. R.; Pople, J. A.;, Ab Initio Molecular Orbital Theory. 1986, New York: Wiley.

39. Nomura, K.-i., et al., Dynamic Transition in the Structure of an Energetic Crystal during Chemical Reactions at Shock Front Prior to Detonation. Physical Review Letters, 2007. 99(14): p. 148303.

40. Rappe, A.K. and W.A. Goddard, Charge Equilibration for Molecular-Dynamics Simulations. Journal of Physical Chemistry, 1991. 95(8): p. 3358-3363.

41. van Duin, A.C.T., et al., ReaxFF(SiO) reactive force field for silicon and silicon oxide systems. Journal of Physical Chemistry A, 2003. 107(19): p. 3803-3811.

42. van Duin, A.C.T., et al., Atomistic-scale simulations of the initial chemical events in the thermal initiation of triacetonetriperoxide. Journal of the American Chemical Society, 2005. 127(31): p. 11053-11062.

43. Chenoweth, K., A.C.T. van Duin, and W.A. Goddard, ReaxFF reactive force field for molecular dynamics simulations of hydrocarbon oxidation. Journal of Physical Chemistry A, 2008. 112(5): $p$. 1040-1053.

44. Chenoweth, K., A.C.T. van Duin, and W.A. Goddard, ReaxFF Reactive Force Field for Molecular Dynamics Simulations of Hydrocarbon Oxidation. The Journal of Physical Chemistry A, 2008. 112(5): p. 1040-1053.

45. Nomura, K.I., et al., Dynamic transition in the structure of an energetic crystal during chemical reactions at shock front prior to detonation. Physical Review Letters, 2007. 99(14): p. - .

46. Nakano, A., et al., De novo ultrascale atomistic simulations on high-end parallel supercomputers. International Journal of High Performance Computing Applications, 2008. 22(1): p. 113-128.

47. Nakano, A., et al., A divide-and-conquer/cellular-decomposition framework for million-to-billion atom simulations of chemical reactions. Computational Materials Science, 2007. 38(4): p. 642652. 